\title{
On the Syntax and Pragmatics Interface: Left-peripheral, Medial and Right-peripheral Focus in Greek
}

\author{
Konstantina Haidou \\ School of Oriental and African Studies, University of London \\ 109614 esoas.ac.uk
}

\begin{abstract}
The present paper explores the extent to which narrow syntax is responsible for the computation of discourse functions such as focus/topic. More specifically, it challenges the claim that language approximates 'perfection' with respect to economy, conceptual necessity and optimality in design by reconsidering the roles and interactions of the different modules of the grammar, in particular of syntax and phonology and the mapping between the two, in the representation of pragmatic notions. Empirical and theoretical considerations strongly indicate that narrow syntax is 'blind' to properties and operations involving the interpretive components - that is, PF and LF. As a result, syntax-phonology interface rules do not 'see' everything in the levels they connect. In essence, the architecture of grammar proposed here from the perspective of focus marking necessitates the autonomy of the different levels of grammar, presupposing that NS is minimally structured only when liberated from any nonsyntactic/discourse implementations, i.e., movement operations to satisfy both interface needs. As a result, the model articulated here totally dispenses with discourse projections, i.e. FocusP.
\end{abstract}

\section{Introduction}

A key assumption of generative grammar, from very early stages of the theory (e.g., Chomsky 1965) to the present, is that of 'syntactocentrism': that is, that the narrow syntax is the fundamental generative component of the computational system and that the phonological and semantic components are 'interpretive'. According to this view, the infinity of language, which Chomsky takes to be one of its essential and unique characteristics, arises from exactly one component of the grammar: the recursive phrase structure rules — or in the Minimalist Program (e.g., Chomsky 1995), the operations of Select and Merge. Whatever recursive properties phonology and semantics have, they are a reflection of interpreting the underlying recursion in syntactic phrases. Consider the following passage from Chomsky (1965: 136): 'We are in effect assuming that the semantic interpretation of a sentence depends on its lexical items and the grammatical functions and relations represented in the underlying structures in which they appear.' 
A departure from this syntactocentric view came from the phonology of the mid-1970s, where, in particular, Autosegmental Phonology (Goldsmith 1976; Liberman \& Prince 1977) proposed several independent tiers connected by association lines. One claim of this phonological research was that intonational contours were larger phonological units not derived by erasing syntactic brackets and re-bracketing, but autonomous phonological types in the prosodic hierarchy. Thus, the connection of syntax to phonology was not seen as derivational, but rather involved constraints. On this view, PF is part of phonological structure, and not a late or low level of narrow syntactic structure. This is shown in (1), where the intonational phrasing does not correspond to any standard syntactic units.

(1) Syntactic bracketing:

[This] [is [the cat] that chased [the rat [that ate [the cheese]]]]]]

Phonological bracketing:

[This is the cat] [that chased the rat] [that ate the cheese ] (Chomsky 1965)

On this view - one at odds with syntactocentrism - phonology consists of a generative system independent of syntax and related to it by interface rules. The important feature of these interface rules is that they do not 'see' everything in the levels they connect. For example, stress rules do not know about syllabic onsets, and the syntax-phonology interface does not know all of the details of syntactic embedding or of phonological segments. If we extend this line of thought to the syntax-semantics interface, we can see what it too must be 'blind' to syntactic phenomena such as agreement, structural case or verb position; and to semantic phenomena such as aspectual coercion and reference transfer.

The basic claim of this paper is that information structure units, such as the topic and foci conveyed by stress or intonation in many languages, necessitate an approach to grammar in which the phonological and semantic components are independent modules which can be directly available to each other, bypassing syntax. This is strongly implied by the analysis provided here for the discourse functions of a free word order language like Greek. In this respect, we follow Brody (1995), Jackendoff (1997), Reinhart (1995) and Szendröi (2001), among others, in claiming that the grammar should allow for direct PF-LF association without the mediation of syntax.

The outcome of such an approach, from a formal point of view, is a model in which phonology and semantics interface with syntax at the same level. Hence, we follow the main insights of Jackendoff's (1997) hypothesis of Representational Modularity, in that the informational structure of the mind strictly segregates phonological, syntactic and conceptual representations from each other. Each lives in its own module, and there can be no mixed representations that are, for example, partly phonological and partly syntactic. 
Rather, all coordination among these representations is encoded in correspondence mapping rules. ${ }^{1}$

The natural question that arises from such a view is the following one: if we allow PF to access LF directly and vice versa, then what is the role of NS? What is left for NS to do? Probably, the answer lies in the assumption of trying to give NS a more simple structure. We argue that NS is free from semantics and more particularly the semantics of discourse notions, such as focus or topic. A fuller description and discussion of the Greek word order facts in sections 4 and 5 will enhance this view.

The present study applies the above assumptions to the syntax-prosody interface, describing information structure in Greek in terms of parallel representations licensed by interface rules. Section 2 rejects Chomskian assumptions about economy in favour of a direct PF-LF connection without the intervention of NS and the view that prosodic information is available at conceptual structure or C-I. Section 3 briefly presents focus strategies in different languages and proposes that in Greek these strategies are optional, given that they have no immediate effect on the semantic focus interpretation. Section 4 presents the word order facts and proposes that the role of syntax in the realization of focus in Greek is smaller than previously thought. Section 5 argues for a unification of focus position, showing that there are no interface differences between two distinct foci in Greek. It also predicts that the syntax of focus is uniform - that is, that both contrastive and information focus can occupy any position in the clause ex-situ or in-situ. Finally, section 6 presents my proposal for syntax-prosody mapping, which accounts in a uniform way for the three attested focus structures in Greek, namely left-peripheral rightperipheral and medial. Section 7 summarizes and offers some concluding remarks.

\footnotetext{
${ }^{1}$ Evidence for such an approach comes from late lexical insertion. In mainstream generative grammar, words get into sentences by being inserted into syntax by lexical insertion. But Jackendoff (1997), for example, has argued that lexical insertion has to be delayed until SStructure (see also Di Sciullo \& Williams 1987; Koster 1987; Halle \& Marantz 1993 for similar proposals). The reason for this is that a lexical item is a mixed representation, an interface rule which licenses the linking of phonological, semantic and syntactic information. The information that a particular word is tree and not flower has to be communicated between phonology and conceptual structure, in order for someone to utter what they mean. This cannot be performed via syntax because only the syntactic features of a word are what syntax can see, since both of the above words are syntactically indistinguishable. Syntax does not need to drag through a derivation extra phonological and semantic pieces of information inertly. Most differentiation of words is by virtue of sound and meaning structures, since lexical items are not finely individuated in syntax, but rather in semantics and phonology.
} 


\section{Minimalism, Economy and the Interfaces}

The relation between the meanings and the articulations of expressions that is assumed in minimalist research is an indirect one, mediated by the syntax. For example, the language faculty as described by Chomsky $(1995,2000)$ consists of the syntax and the lexicon, which interact with the 'articulatory-perceptual' (A-P) and the 'conceptual-intentional' (C-I) systems at the interface levels PF and LF, respectively. On this view, a given language is a procedure for constructing sound-meaning pairs out of items selected from the lexicon, the members of these pairs constituting 'instructions' for the relevant performance systems.

Chomsky describes this procedure for constructing such sound-meaning pairs as a derivation which 'converges' if the representations that it yields satisfy a 'Principle of Full Interpretation' at the two relevant interface levels, PF and LF (1995: 219-220). Chomsky takes the convergence of a derivation to involve only its interpretability at both interface levels, there being 'no PF-LF interactions relevant to convergence'. This seems to leave no space for any direct communication between PF and LF, since on this view the performance systems access phonetic and semantic information independently.

Since this Chomskian view of the grammar permits PF and LF to interact only by way of syntax, it permits no principles, filters, rules or definitions that simultaneously and directly refer to both pragmatico-semantic and prosodic information, since there is no place in the grammar where such filters or principles could operate. The basic implication is that the interaction of phonology with the rest of the grammar is limited to the interface with syntax such that the output of the syntactic component constitutes the input to the phonological component (with the possible intervention of readjustment rules).

What I shall attempt to do in this study is to show that such a theory of 'split interfaces' offers no way to capture direct correlations between A-P interpretation, related to the PF interface level, and C-I interpretation, related to LF, which emerge especially in the computation of discourse functions. The investigation of such discourse functions will be my main concern here, although there is a great deal more empirical as well as theory-internal evidence against such an account. ${ }^{2}$

Focus is one of the several linguistic phenomena which appear to require a multidimensional approach to the grammar. Focus is not unique to any of the interfaces or to syntax. Recent research in this area shows that a uniform analysis of focus phenomena requires the examination of a number of factors. For instance, focus is realized with stress or accent in a number of languages and many authors have assumed that a focused constituent will always carry

\footnotetext{
${ }^{2}$ For a fuller exploration of this evidence, see Haidou, forthcoming.
} 
the main stress (e.g., Cinque 1993; Reinhart 1995; Zubizarreta 1998). Such a direct relation between stress and focus cannot be captured in minimalist terms, where even semantic features such as [+focus] and phonological features such as [+stress] cannot be justified by Full Interpretation (FI) (cf. Chomsky 1995).

Such a direct relation between stress and focus can be captured only in a framework where phonological information, which is eventually relevant for the interaction of the grammar with the articulatory and auditory mechanisms, is independent of syntactic or semantic information, which in due course interacts with the conceptual-intentional system. Within such a framework, syntactic information and phonological information are simultaneously available in the grammar, and the direct relation between stress and focus can easily be accounted for. In other words, we need to reject the hypothesis that no interaction between PF-LF is possible.

Thus, I argue that the standard Minimalist conception of the architecture of grammar is inadequate in the sense that it has to be customized to allow for prosodic information to interface with semantico-pragmatic structure, in order to capture the basic intuition that prosodic information has an effect on semantic and pragmatic structure. ${ }^{3}$ The claim that prosody is should be able to influence the semantico-pragmatic structure is discussed in section 4.

To satisfy economy considerations, the analysis proposed here dispenses with movements for discourse reasons, since they do not have any justification in the grammar, as well as with stress-driven movements, since these, as I discuss in section 5, impose greater violations of economy than feature-based grammars. ${ }^{4}$ Rather, economy is fully satisfied in the sense that the relation between focus and stress is accounted for via mapping processes that directly relate the interfaces without syntactic considerations. This is the analysis proposed in section 6 .

In what follows, I will briefly examine different focus-marking strategies in different languages, showing that languages use different devices to identify

\footnotetext{
${ }^{3}$ It has long been observed that intonational patterns may have different pragmatic effects (Bolinger 1965; Halliday 1967; Jackendoff 1972; Ladd 1996; Lambrecht 1994; Steedman 2000). It has also been observed that intonation can have an effect on semantic interpretation; for example, in German, different intonational patterns yield different scope readings (e.g., Büring 1997; Féry 1993; Krifka 1998).

4 I have argued elsewhere (see Haidou 2003, 2004) that stress-driven movement or scrambling operations for focus-internal reasons (scrambling with deaccenting or scrambling with stress assignment) add unnecessary complications to the grammar and violate economy considerations, since the positing of, e.g., movement to a Focus Phrase makes use of a syntactic mechanism, movement, but motivates it only with semantic considerations. I therefore allow such operations only in languages where they satisfy an inherent intonational property. For instance, in Hungarian, stress is by default leftmost; and since stress follows the focused constituent, p-movement rearranging the canonical ordering of the sentence is justified. However, as will be shown below, this cannot be the case in Greek.
} 
focus, some of these devices rendered obligatory by specific semantic or syntactic requirements. However, this study will concentrate on the case of languages, such as Greek, where the occurrence of focus in a number of positions is optional and the mechanisms that realize it render it optional too. The evidence presented in section 4 raises a basic question about syntax and discourse function: namely, whether discourse functions are or are not dependent on particular syntactic configurations.

\section{Focus Strategies across Languages}

The realization of focus involves many different linguistic components syntax, phonology, morphology, and pragmatics — one or more of which plays a prominent role in the encoding of focus in a given language. In particular, languages can be thought of as parametrized with respect to their use of morphology or syntax to identify discourse functions. Morphological marking appears to figure, for example, in Navajo (Vallduví \& Engdahl 1996, citing Schauber 1978) and a number of Bantu languages (Watters 1979; Odden 1984; Hyman \& Watters 1984); whereas the syntactic marking of focus has been claimed for Catalan (Vallduví 1992; Vallduví \& Engdahl 1996), and also for English (Rochemont 1986, 1998; Rochemont \& Culicover 1990), Spanish (Zubizarreta 1998), Hungarian (Horvath 1986; É. Kiss 1998), Greek (Tsimpli 1995, 1997), Hindi (Kidwai 2000), and other languages. Below, I present example sentences from languages that have been argued to mark focus by syntactic means - in particular, word order:

a. Tengap este MARINAK mutattam be Pétert

HUNGARIAN Last night Mary-dat introduced-I perf Peter-acc 'It was to Mary that I introduced Peter last night'

b. Tengap este be mutattam Pétert MARINAK Last night I introduced Peter TO MARY'

(3) a. Del CALAIX la Nuria (els) va truer els esperons

CATALAN of.the drawer the Nuria them has taken.out the spurs 'It was out of the drawer that Nuria took the spurs'

b. La Nuria (els) va truer DEL CALAIX els esperons

'Nuria took the spurs OUT OF THE DRAWER.'

(4) a. AnNalle Mikko antoi kukkia

FINNISH Anna.adess Mikko gave flowers 'It was to Anna that Mikko gave flowers'

b. Mikko antoi kukkia ANNALLE Mikko gave flowers TO ANN 
However, in languages like English, which use both phonological and syntactic means (e.g., cleft and pseudo-cleft constructions) for signalling focus, it is not clear that morphological and syntactic encodings of focus are entirely independent of phonological encoding. Therefore, languages should also be thought of as parametrized with respect to the marking of focus by prosodic cues, including segmental phrasing and prominence (stress or pitch accent). Note that there is further parametrization within the phonological system, since prosody can identify focus with the assistance of other linguistic levels. We find this in certain languages, where focus, intonation and word order can conflict with each other and languages resolve these conflicts by sacrificing one of these:

A: Canonical pattern of prosodic phrasing:

a. ENGLISH: (John bought the newspaper $\left.)^{\mathrm{iP}}\right)^{\text {PhonP }}$

SVO

b. ENGLISH: (JOHN bought the newspaper $\left.)^{\mathrm{iP}}\right)^{\text {PhonP }}$

SVO

or B: Canonical constituent order (for prosodic requirements):

(6)

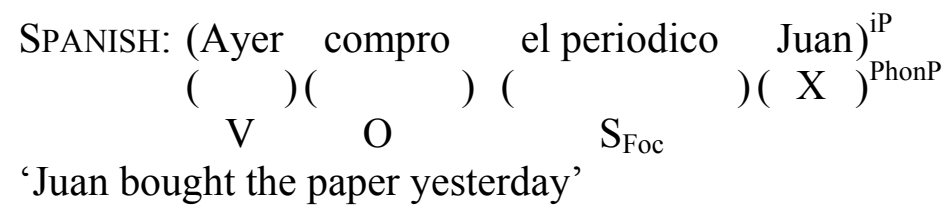

VOS

or

C: Both:

(7) a. GERMAN: Es wird... dass (der Kanzler den Aussenminister ernennt) SOV

$\mathrm{X}$

$\mathrm{S}_{\mathrm{Foc}}$
$\mathrm{O}$ $\mathrm{V}$

b. GERMAN: Es wird... dass (den Aussenminister der Kanzler ernennt)OSV

$\mathrm{O}$



)$^{\text {PhonP }}$

'It is... that the chancellor nominates the foreign-minister'

(Büring \& Gutierrez-Bravo 2002)

Thus, languages which are claimed to mark focus by phonological means do not always exploit the same type of phonological marking or the identification of focus can rely on the syntax-prosody interaction. In this respect, there are different prosodic means for marking focus.

One of the main arguments of this study is that, although the crosslinguistic variation just described shows that languages may use one or more of the above strategies to identify focus, the different strategies employed for each language nonetheless make a strategy obligatory, especially when the 
occurrence of a specific strategy is necessarily related with a specific semantic focus interpretation and the opposite result would result in ungrammaticality. Thus, the obligatory nature of focus movement in a language has to account for a special interpretational pattern, such as exhaustive, contrastive, or completive focus, or a certain phonological requirement.

What I will show for Greek, however, is that, although different strategies have been proposed especially for the syntactic domain, these strategies are all optional, since they are not related with a specific focus interpretation. I show (contra Discourse Configurational approaches) that there is no difference in the semantic focus interpretation in the different spell-out positions of focus. This means that Greek allows the same semantic type of focus to be instantiated by different word orders. Since Greek, as a relatively free word order language, uses both word order and prosody for focusing reasons, I will argue that it requires a special type of modification to the analysis of the syntax-prosody interface.

\section{Word Order and Information Structure}

In this section, I will investigate the interaction between intonation, information structure and word order in Greek. To keep the investigation as relevant as possible, I will look only at one set of canonical and non-canonical or 'scrambled' constituent orderings of mono-transitive sentences. 5

Two prosodic patterns will be the focus of this section. The first is the neutral prosodic pattern which characterizes broad focus contexts in declarative sentences. ${ }^{6}$ The second prosodic pattern is the non-neutral one, with non-final accent placement realized as narrow focus. ${ }^{7}$

In the neutral prosodic pattern, the typical structure is an SVO sentence structure. In order to examine the interaction between information structure and syntactic position, I will consider all the logically possible constituent orderings of this sentence type. Given that this structure has three major

\footnotetext{
${ }^{5}$ In Greek all the logically possible word order variations for a simple sentence like that in (9) are grammatical. Studies over the past twenty years have shown that these word order variations do not have the same meaning. More specifically, Agouraki (1990), Alexiadou (1999), Philippaki-Warburton (1982, 1985), Tsimpli (1990, 1995, 1997), Tsiplakou (1998), and Tzanidaki (1994), among others have revealed that communication functions such as topic and focus in Greek are syntactically encoded.

${ }^{6}$ In the neutral pattern no word carries narrow focus except, perhaps, for the final or rightmost content word, which carries the nuclear pitch accent, followed by a combination of phrase accent and boundary tone. According to Arvaniti \& Baltazani (2000), the typical melody tune of a Greek declarative in an 'all-new' context, broad focus, is $\mathrm{H}^{*}$ accent, followed by $\mathrm{L}^{-} \mathrm{L} \%$ boundary tone.

${ }^{7}$ The accent coincides with any other material in the sentence except for the final element. The typical melody tune of narrow focus is realized as $\mathrm{L}+\mathrm{H}^{*}$ nuclear pitch accent.
} 
constituents (Subject, Verb, Object), the number of possible orderings is six. It is clear that a default or canonical order of the nominal arguments is required for getting a broad sentence focus and focus projection or ambiguity possibilities. In addition, the verb can occupy the initial or the medial-string position excluding the final position. I will look first at word order realized under neutral accent placement.

In Greek, for a sentence to be compatible with an 'all-new' context sentence-broad focus, the prosodic/intonational component requires a canonical ordering of the nominal arguments where the verb either precedes the subject or immediately follows it and the final verb position is disallowed. None of the other ordering possibilities can produce an 'all-new' broad focus sentence because they reveal focus domains which are smaller than the whole sentence; only SVO and VSO are compatible with an 'all-new' context. The interesting fact, though, is that all of the orderings allow for a narrow focus on the last constituent, which carries the nuclear stress. ${ }^{8}$ Note also that SVO and VSO include the object in the final position, which receives nuclear stress. ${ }^{9}$

(8) a. Kanena neo?

Any news?

b. i kivernisi tha afksisi ti forologia SVO $\sqrt{ }$ the government-nom will-fut raise-3sg the taxes-acc 'The government will raise the taxes'

c. $*_{i}$ kivernisi ti forologia tha afksisi

SOV

d. *tha afksisi ti forologia i kivernisi

VOS

e. *ti forologia tha afksisi i kivernisi

OVS

f. *ti forologia i kivernisi tha afksisi

OSV

\footnotetext{
${ }^{8}$ It is interesting to point out that there is still a wider choice of answers that accommodate an all-focus question. Constituent orders such as SVO, OVS, VOS and, generally, verbinitial orders are permitted as answers to an all-focus question in an appropriate context and with special intonation.

${ }^{9}$ Both of these orders in Greek allow for focus ambiguity. This is interesting since it implies that the ordering of the constituents in the utterance with respect to each other is responsible for focus projection. This strengthens the role of word order in the realization of information structure. However, this does not imply that rearrangements in the syntactic constituent ordering are driven by discourse or information structure - a crucial claim in this section and throughout the paper. Rather word order and its rearrangements are there to facilitate the domains of licensing or appearance of focus or given material. Word order allows focus to project or not. That is, I claim, the main function of the syntactic component, and not to trigger syntactic processes for accommodating foci or topics. In Haidou 2004, I show that word order is a much smaller factor in the realization of Information Structure than accent placement or clitic-doubling.
} 
Let us now consider VOS and OVS orders with neutral stress - that is, stress on the rightmost constituent, the subject. Both of these are answers to questions that license narrow focus on the subject, as shown in (9): ${ }^{10}$

(9) a. Pjos afksise ti forologia?

Who raised the taxes?

b. afksise ti forologia I KIVERNISI

VOS

c. ti forologia afksise I KIVERNISI

OVS

'The government raised the taxes'

The last orders are the verb-final ones, that is, SOV and OSV. I assume that both orders license narrow focus on the verb. Verb final orders, though grammatical, are understood in the literature as less acceptable. However, if followed by clitic doubling of the object NP, their acceptability improves. Keller \& Alexopoulou (2000) argue that these orders become fully acceptable if more material is added after the verb. Note that the context in (10) is a correction context which usually induces contrastive focus. The contrast here is between 'lowering' and 'raising' (the taxes):

(10) a. Ti ekane i kivervisi me ti forologia?

what did-3sg/PS the government-nom with the taxes-acc?

Tin KATEVASE?

it-cl-dropped-3sg

'What did the government do with the taxes? Did it LOWER them?'

b. (Ohi,) ti forologia $\mathrm{i}$ kivernisi tin AFKSISE OSV

(no,) the taxes-acc the government-nom it-cl raise-3sg/PS

c. (Ohi,) i kivernisi ti forologia tin AFKSISE SOV

(no,) the government-nom the taxes-acc it-cl raise-3sg/PS

' $(N o$,$) the government raised the taxes'$

Let us look at the non-neutral prosodic patterns. To accomplish this task, we need to look at all the possible constituent arrangements and the prosodic prominence from constituent to constituent. We have already seen the six possible constituent orderings under neutral intonation, given the fact that we have six possible word orders. What remains is to consider the 12 additional possibilities shown in (11)-(12).

\section{OBJECT FOCUS (FINAL, MEDIAL, LEFT-PERIPHERAL)}

a. i kivernisi afksise tus misthous? the government-nom raise- $3 \mathrm{sg} / P S$ the salaries-acc/PL?

'Did the government raise the salaries?'

\footnotetext{
${ }^{10}$ However, none of the above orders can license a VP or sentence focus. Subject-final structures cannot be answers to VP or V focus questions. More specifically, the focus on the subject cannot project focus to the verb.
} 
b. Ti afkise i kivernisi?

what raise-3sg/PS the government-nom?

'What did the government do?'

c. i kivernisi afksise TI FOROLOGIA

$\operatorname{SV} \underline{\boldsymbol{O}}$

the government-nom raise- $3 \mathrm{sg} / P S$ the taxes-acc

'The government will raise the taxes'

d. TI FOROLOGIA i kivernisi afksise

e. afksise TI FOROLOGIA i kivernisi

f. i kivernisi TI FOROLOGIA afkise

g. TI FOROLOGIA afksise i kivernisi $\underline{\boldsymbol{O} V S}$

h. afksise i kivernisi TI FOROLOGIA

(12) SUBJECT FOCUS (FINAL, MEDIAL, LEFT-PERIPHERAL)
a. Pjos afkise ti forologia?

who-nom raise-3sg/PS the taxes-acc

'Who raised the taxes?'

b. I ANDIPOLITEUSI, afkise ti forologia?

the opposition-nom raise-3sg/PS the taxes-acc

'Was it the OPPOSITION that raised the taxes?'

c. I KIVERNISI afksise ti forologia

d. I KIVERNISI ti forologia afksise

e. afksise I KIVERNISI ti forologia

f. ti forologia I KIVERNISI afksise

g. ti forologia afksise I KIVERNISI 
(13)

VERB FOCUS (FINAL, MEDIAL, LEFT-PERIPHERAL)

a. i kivernisi ERIKSE ti forologia?

the government-nom drop-3sg/PS the taxes-acc?

'Did the government lower the taxes?'

b. Ti ekane i kivernisi me ti forologia?

what did-3sg the government-nom with the taxes-acc?

'What did the government with the taxes?'

c. i kivernisi AFKSISE ti forologia $\quad \mathrm{S} \underline{\boldsymbol{V}}$

d. Ti les? ti forologia AFKSISE i kivernisi $\quad \mathrm{O} \underline{\boldsymbol{V}}$

e. AFKSISE i kivernisi ti forologia $\underline{\boldsymbol{V}} \mathrm{SO}$

f. AFKSISE ti forologia i kivernisi $\underline{\text { VOS }}$

g. ti forologia i kivernisi tin AFKSISE OS $\underline{\boldsymbol{V}}$

Given the examples in (8)-(10) and (11)-(13), we can arrive at the following generalizations. Under neutral intonation (rightward prominence) different word orders realize different focus domains. Thus, we can propose the following generalizations regarding the interaction between stress placement and information structure.

GENERALIZATION 1: An identical intonational structure can realize different information structures.

Under neutral prosody - that is, accent or stress assigned on the final constituent, e.g. $\mathrm{H}^{*}$ or $\mathrm{L}+\mathrm{H}^{*}$ - we can derive different focus domains or different partitions of information structure. This is the case for the set of examples shown in (8)-(10).

The second generalization is that under non-neutral intonation pattern, one and the same word order can provide different focus structures.

GENERALIZATION 2: One word order can realize different information structures.

In fact, in all of the sets of examples it is obvious that SVO word order is involved in at least five focus domains. These include both broad domains sentence-focus and VP-focus - as well as narrow domains - O-focus, Sfocus and O-focus. Also, VOS word order can realize at least four information structures: that is, VP-focus, V-focus, O-focus and S-focus. Similarly, OVS can realize at least two narrow focus domains: O-focus and $\mathrm{V}$-focus and, probably on a marked context, an S-focus. VSO has also realizes an all-focus domain, a V-focus and an S-focus.

Now the reverse is also true: under marked or non-neutral intonation a certain information structure or focus context can be realized by more than one word order. Any focus context can be realized by the focus constituent in initial, medial or final position. For instance, an all-focus context or a wide 
domain can be realized by VSO and SVO word orders, and as shown in (8), by OVS and VOS in special contexts (optionally followed by clitic doubling of the object NP). This claim is consistent with generalization 3 .

GENERALIZATION 3: A certain information structure can be realized by a range of word orders.

A subject focus context can be realized by, for example, SVO, VOS, OVS, and VSO orders. Similarly, an object focus context can be realized by a number of word orders: object-initial OVS and OSV orders, object-final SVO, and object-medial SOV and VOS orders.

Of course, certain restrictions apply regarding the word orders that can accommodate a certain information structure or the same focus context. Moreover, certain word orders may be preferred in a given context. These restrictions on the information structure of the Greek language hold as a result of a combination of syntactic and phonological factors. ${ }^{11}$

Examination of the data also supports generalization 4:

GENERALIZATION 4: Different intonational structures can realize the same information structure.

Compare a marked prosodic pattern or a 'contrastive' stress pattern with a normal or neutral intonation pattern, for example, OVS as in (11) with SVO as in (8). The information structure division is the same in both structures; the verb is focused and the subject and object are given or part of the ground. Let us say that one intonation pattern is marked and the other is unmarked. OVS which carries a preverbal focus is marked by definition and SVO is unmarked since the object that carries the stress is the rightmost constituent. Thus, the same information structure, that is, focus on the object, can be followed by different intonational means, unmarked prosody versus marked prosody.

The data above show that the same type of prominence can signal different types of focus domains. This argument supports the view that prominence itself is not sufficient to say what the exact focus domain is each time, because it is ambiguous with respect to focus. As argued in Haidou 2004, focus projection, as in SVO structures, is unexceptional because it does not have to be postulated anywhere. If we observe the evidence closely, the role of the relation between focus and stress lies systematically in the directionality of prominence: all that is sufficient and necessary is rightmost prominence. I will propose in section 6 that the outcome of the focus projection or of the wide versus narrow focus domain is the result of the alignment or placement of rightmost boundaries of constituents. Therefore, stress assignment on the right

11 The generalizations can be described in terms of formal constraints that restrict the realization of information structure in the language. For a fuller picture of the role of the different components of grammar that mark the realization of information structure in Greek and how the influence of these components is ranked, see Haidou 2004. 
periphery will indicate the focus domain with the consequence that the right border of a constituent will coincide with its right domain of prominence. Any other stress pattern will preclude projection, as a result of misalignment of structures, since projection is not motivated independently. It is just the end product of ambiguity between sequences of several rightward constituent borders.

Assuming that syntax 'accommodates' or 'facilitates' the representation of focus in the grammar correctly predicts that the interaction between prominence and focus cannot be anything else than one-to-many because the focus domain is not always isomorphic with the stressed constituent that carries the pitch accent and only one-to-one when focus coincides with the stressed element. I argued in section 2 that the relation between focus and prominence need not be defined in syntax, that is, by feature assignment. Syntax is not responsible for the actual focus that will be chosen each time a sentence is uttered. The role of syntax, which involves the syntactic machinery available in each language - that is, word order, scrambling, clitic doubling, and clefting — is, to use Vallduvi's (1992) term, to 'package' the information chosen by discourse requirements, with the help of intonation or word order or both so as to 'feed' it directly to the interpretive components, i.e. PF and LF.

It appears that focus ambiguity or wide focus domains do not arise as an immediate result of the indirect (one-to-many) computation between stress and focus in the syntax. Rather, focus marking is syntactically unconstrained (Schwarzschild 1999). Focus-markers are freely assigned. The focused constituent will always receive the main stress. That is, focus will always be marked by prosodic means and not by syntactic F-markers. As is obvious from the data above, prosodic prominence can be assigned to any constituent without exception.

My claim is that focus ambiguity can be resolved as the end-product of the interaction between intonation and discourse, and not directly at the correspondence between prominence and focus. It is in fact because each interpretation is linked directly with a specific intonation, defined by discourse conditions, that the output of the grammar is an ambiguous utterance. Thus, discourse requires, and the phonology justifies, the specific positioning of focus. This claim has the further desirable theoretical gain that the phonological information interfaces with the pragmatic component of the grammar, i.e. the conceptual-intentional interface, contra Chomsky (1995, 1999, 2001). This claim also is supported by Haidou (forthcoming) and Szendröi (2001).

Thus, the relation between focus and stress is always one-to-one. Focus is defined by prosody - that is, main stress. The ambiguity only arises in the grammar, where according to discourse requirements one particular interpretation is chosen which encodes the focus by means of a special intonation. The ambiguity occurs not because of a direct or indirect 
relationship between focus and prominence, but rather because of a relationship between phonology and pragmatics/discourse. In this sense, focus can be considered a pragmatic phenomenon and not a syntactic one. The postulation of focus in the syntax is too restricted to derive the correct predictions regarding the stress-focus correspondence and the notions of new and given information. Hence, it is up to discourse conditions, rather than syntax, to determine whether a derivation with a particular stress is appropriate in a given context.

One could argue that languages behaving like Greek might be optionally hierarchically structured. However, given that prosodic effects when they come into play are much stronger, focus turns into a PF phenomenon or rather a multiple phenomenon, an outcome of the parallel interaction of the interfaces, PF-Information Structure and LF-Conceptual Structure.

I thus propose that under neutral or marked prosodic patterns, the pragmatics-discourse component of the grammar allows multiple word order variations as equally possible focus answers to only one question. ${ }^{12}$ I also propose that the role of word order is weaker than thought in earlier analyses. The role of syntactic word order is just to facilitate or mediate the requirements of discourse/context in the realization of information structure. It just facilitates the position of a focus or a topic/given constituent, which in turn will be the outcome of a direct interaction between LF and PF (see Haidou 2004 for detailed discussion). Discourse functions such as focus and topic are accommodated by syntax as purely syntactic objects, but their interpretation is a task further undertaken by PF and LF and not the syntax itself. Syntax is autonomous in the sense of driving computations for a number of different reasons, including case, agreement, EPP, and verb position.

From a formal point of view, I argue, in line with Chomsky (2002), that discourse-related phenomena do not involve the licensing of corresponding features in designated pre-existing functional projections to justify the discourse-related effects they are assigned. Movement operations in Chomsky 2002 are triggered only by uninterpretable syntactic features in the narrow syntax. In effect, the discourse properties of syntactic constituents receive the relevant interpretation by the semantic component after the operation SpellOut, provided that the constituents already appear in the relevant position in the architecture of the clause. In turn, what is carried through the syntactic

\footnotetext{
${ }^{12}$ In the marked case, the interpretation changes from wide to narrow focus. The difference between the current proposal and others is the claim that 'narrow' versus 'broad' interpretation do not necessarily imply notions such as 'identificational' or 'contrastive'. Narrow focus is not always preverbal and contrastive or identificational (contra É. Kiss 1995a, 1998). It is not the case that ex-situ focus equals identificational or contrastive focus interpretation, since it is also not the case that in-situ focus equals new-information focus. Thus, there seems to be an unusual asymmetry between sentence position, interpretation and prosodic pattern.
} 
derivation, visible to syntactic rules, is not the whole lexical item, but only its syntactic features. On recent Minimalist assumptions, the only formal trigger for syntactic movement is an EPP feature, since Case and Agreement can be satisfied covertly via Agree. Sifaki (2003) further extends the argument by assuming that this EPP feature could be available in every functional projection of the clausal hierarchy. The lexical items that enter the derivation carrying or not carrying - depending on one's favourite theory of lexical insertion - their discourse-related properties are arranged in the narrow syntax in displaced positions. This displacement, which results in different word orders, is triggered for EPP-satisfaction reasons (for further details of this proposal, see Sifaki 2003). Accordingly, the structure of the clause is built up in a manner that respects and directly feeds the operations relevant only to $\mathrm{PF}$ and LF, so that the corresponding properties of the displaced constituents receive an interpretation.

Thus, pursuing the assumptions of section 2, I extend the above analysis by arguing that it would be an undesirable violation of economy considerations if the interfaces (PF and LF) had to rearrange the already organized (displaced) discourse-related syntactic constituents to satisfy their interpretational requirements. Such process would add unnecessary complications to the grammar and would violate the independence of levels of representation proposed in the current analysis. Furthermore, if we allow PF and LF to derive movement operations in the narrow syntactic component to satisfy their needs, we immediately violate the Inclusiveness Principle (see Chomsky 1995: 225). This principle states that outputs consist of nothing beyond properties of items of the lexicon - in other words, that the interface levels consist of no more than the rearrangement of lexical features. This means that [+Focus] or (hypothetical) [+Stress] features driving computations to satisfy interface needs are only stipulations and have no justification in the narrow syntax. Thus, the current proposal disallows movement by either LF or PF as conceptually, theoretically and empirically redundant. Moreover, it gains extra theoretical 'simplification' since it accounts for discourse-related phenomena without discourse projections.

There is an additional reason why syntax plays a minimal role in the articulation of information structure. Recall generalizations 2 and 3, which state that one word order can realize more than one information structure and that the same information structure can be realized by a number of word orders. This means that there is no isomorphism between syntax and discourse, since a single information structure may correspond to more than one syntactic structure. If one information structure can be realized by more than one word order, this strongly suggests that the different syntactic positions that focused or given constituents are found in may vary. For instance, in cases of O-focus, the object can be realized postverbally, preverbally or in string-medial position, either on its own or supported by 
clitic-doubling. Note that for the same information structure to be realized in more than one position or by a number of different word orders, the focused element must have the same semantic interpretation in any of these positions. The Greek data in (8)-(13) have shown that 'ex-situ' or 'in-situ' focus can clearly have the same semantic interpretation, being contrastive, exhaustive, or informational. So, it seems that the relation between semantic interpretation and focus is not one-to-one. ${ }^{13}$ Although the prosodic factor (prominencestress) remains stable, it seems that the relation between syntax and semantics is one-to-many. This is the main topic of discussion in section 5 below.

The big question now is: if the pragmatics-discourse component of the grammar allows a certain information structure to be associated with more than one word order without any difference in tinterpretation, is any ordering permitted by the grammar under a single focus question or are there any restrictions? In other words, does the grammar exhaust all its logical ordering possibilities or are certain possibilities more acceptable than others? As it happens, there are orderings which speakers clearly do prefer and whose frequency of use is higher.

Here, the main claim is that not all ordering variants that answer a focus question come with the same strength of acceptability. Rather, the grammar decides that certain word orders satisfy an information structure more efficiently than others. The argument here is that word orders do not all carry exactly the same information weight. However, the grammar allows multiple possibilities, i.e. $\mathrm{n} \geq 1,2,3$, etc. Which ones will best satisfy a certain information structure partition depends on how speakers' choices match relevant discourse requirements. I leave the discussion open on this matter, pending further research. It might be worth pointing out, though, that the optimal choice between possible orders for a given context and intonation is plausibly attributed to performance or processing effects. However, investigating this possibility would require natural speech corpora and is thus beyond the scope of the current study.

To conclude this section, I have suggested that the syntax of discourse constructions should be independent of the discourse functions encoded (for a similar argument couched in a HPSG analysis, see Alexopoulou 1999). My idea is that the relation between syntax and discourse is non-isomorphic, a particular syntactic structure relating to a discourse function in a one-to-many

${ }^{13}$ This argument has serious implications for the syntax-semantics interface of discourse phenomena, and goes against Discourse Configurational approaches. In the Minimalist framework (Chomsky 1995), the correlation between focus and the grammatical representation of the utterance is strictly determined through a direct and unambiguous relation between the two. Thus, focus is represented directly in the syntax according to the standard view in the generative literature of the 1980s and 1990s (cf. Antinucci \& Cinque 1977; Abraham et al. 1986; Büring 1997; Diesing 1992; Horváth 1986; Jackendoff 1972; É. Kiss 1998b; Rizzi 1997; Rochemont 1986; Vallduvi \& Vilnuka 1998; Zubizarreta 1998). 
fashion. This does not seem to be in the spirit of many Minimalist analyses of constructions with non-canonical word orders, such as focus movement, cliticleft dislocation, and topicalization, which stipulate syntactic operations using distinct phrase structure projections such as FP and TP. On the view being defended here, focus and given elements are represented at a level independent of syntax, i.e., Information Structure (IS), whereas the syntax (probably) carries information related, for example, to agreement, structural case, verb position, EPP, and the formation of relatives; and there is no need to replicate all of the distinctions of one structure in the other.

On this view, syntax is a more concrete and relatively 'flatter' system, carrying fewer abstract features and possibly fewer movement operations, or no movement when possible. Along the lines of Jackendoff (1997), I am arguing, then, that we should abandon the idea that syntax, in the generative sense, replicates mismatches between surface structure and conceptual structure. Conceptual structure (C-I) has a complex architecture made up of levels of semantic units which need have no direct relation to syntactic units.

What all of this suggests is that word order is a weaker factor in the realization of discourse functions than accent/stress placement or prosody. In the next section, I will propose, contra standard assumptions, that there are no interface differences between the two types of focus.

\section{Identificational versus Information Focus in Greek? Towards a Unification of Focus at the Interfaces}

Greek has traditionally been described as having only one focusing strategy: focus fronting (Agouraki 1990, 1993; Tsimpli 1995, 1997; Tzanidaki 1994). However, all the above authors, among others (see also Alexopoulou 1999; Baltazani 2002; Tsiplakou 1998), have recognized that there is evidence for a focus in-situ strategy in the language. Nevertheless, their common assumption is that focus strategies in Greek maintain a rigidly fixed correspondence between the syntactic position of focus and its semantic interpretation. ${ }^{14}$

\footnotetext{
${ }^{14}$ More specifically, Tsimpli $(1990,1995)$ formulates a semantic division between ex-situ and in-situ focus and constantly links ex-situ focus with exhaustive listing interpretation (identificational focus) and in-situ focus with new information focus. In the same fashion, Alexopoulou (1999), though acknowledging the different characteristics of ex-situ and insitu focus, still advocates a mapping which relates the specific positioning of focus with a specific semantic interpretation. Along the same lines, Baltazani \& Jun (1999) defend the same correlation between syntax and semantics, in that the position of the focus phrase corresponds to a specific semantic interpretation. In her semantic analysis, the preposed focus phrase carries exhaustive interpretation caused by the existence of an exhaustive identification (EI) operator. Baltazani also ascribes contrastive interpretation to ex-situ focus and as a result ex-situ focus carries features for both interpretations: that is, [+exhaustive], [+contrastive].
} 
My own research (Haidou 2003, 2004) has offered a different picture of the Greek focus phrase, since it allows for an indirect mapping between syntax and semantics/prosody. Moreover, it argues, contra previous work on the language, that the idea of in-situ focus equalling new information and ex-situ focus equalling exhaustive-identificational properties cannot be sustained for Greek. Given the word order facts presented in this and the previous section, it appears that Greek has different word order options for realizing information structure and satisfying discourse requirements.

In line with Grillia's (2004) arguments, I will proceed by providing additional tests and evidence, both semantic and prosodic, to show that there is no correlation between syntactic position and semantic interpretation (contra É. Kiss 1998). ${ }^{15}$ In a nutshell, this section argues for a merger of ex-situ and in-situ focus structure - that is, a unification of focus (see also Brunetti 2003 for Italian). That is, focus is one and the same phenomenon realized though different positions allowed by the grammar of discourse and exploited by the computational system $C_{H L}$.

This section has two aims. The first aim is to clarify the descriptive facts, in order to establish whether there is a systematic correlation between the syntax and semantics of focus, or whether the interpretation of focus rests purely on discourse-pragmatic factors. The second aim is theoretical: to consider the data in the light of Minimalist considerations, in order to present a unified syntactic analysis of in-situ and ex-situ focus. This in turn relates to broader theoretical issues, concerning 'optionality' in a perfectly economical system.

Assuming the notion of 'interface economy' as proposed by Reinhart (1995) and adopted by Chomsky (2000, 2001a, 2001b), a 'marked' or 'costly' operation is only licensed if, at the interface, the outcome is a distinct interpretation not achieved by the less 'marked' alternative. One empirical question that arises from these considerations is thus the following: if a language has more than one focusing strategy (morphosyntactic and/or phonological), can each of these be shown to correspond to a distinct interpretive goal (hence providing support for the notion of language as an economy-driven system), or are interpretive 'choices' forced by pragmatic factors? Here, I will present arguments in favour of the second option and make the assumption that 'economy' is satisfied if we hypothesize that the two foci have the same syntax, the interpretive differences being only apparent.

The classic analysis of Focus in terms of two different grammatical phenomena is that of É. Kiss (1998), who proposes that there is 'identificational focus' and 'information focus'. In the next section, I will provide arguments against a semantic distinction between these two types of

${ }^{15}$ For syntactic evidence and a detailed discussion of prosodic and semantic evidence, see Haidou 2004. 
Focus, showing that such an approach to Focus cannot be maintained for Greek. In addition, since approaches that maintain that there is a semantic difference between the two foci have also noted variation with respect to the $\mathrm{PF}$ interface - more specifically, the two semantic types of focus, i.e. contrastive and information focus, carry different types of stress, formalized in terms of distinct prosodic rules - evidence will thus be provided that there are no such phonological differences in Greek either.

\subsection{The LF Interface}

The central interpretive property that sets the two foci apart, according to É. Kiss (1998), is the property of 'exhaustive identification'. A focused element expresses exhaustive identification when it identifies a 'unique referent' from the context to be interpreted as focus or part of focus. This property is consistent only with syntactically preposed foci or identificational foci. New information focus which expresses non-presupposed information is not compatible with this property.

The first piece of evidence for this comes from test A, which É. Kiss attributes to Szabolcsi (1981). This test supports the idea that identificational focus expresses exhaustive identification and information focus does not, as follows: given a pair of sentences where the first contains focused co-ordinate DPs and the second contains only one of those focused DPs, if the second sentence is not among the logical entailments of the first, then the type of focus involved is identificational (exhaustive). According to É. Kiss (1998), test A shows that in Hungarian ex-situ focus will always have identificational properties.

(14) a. Mari EGY KALAPOT ÉS EGY KABÁTOT nézett ki magának.-/-> Marya hat-acc and a coat-acc picked outherself-acc 'It was a hat and a coat that Mary picked out herself.'

b. Mari EGY KALAPOT nézett ki magának. Marya hat-acc picked outherself-acc

'It was hat that Mary picked for herself.'

It is the exhaustivity of (14b) that results in the failure of the implication. With respect to the data in (14) above, Baltazani (1999) makes a distinction between contrastive focus and information focus for Greek, as shown in (15), where the former appears only in a preverbal position and always receives an exhaustive interpretation due to the presence of an exhaustive identification (EI) operator.

(15) a. STO YANI KE STI MARIA agorasa padeloni. -/-> to-the John and to-the Mary bought-1sg trousers-acc-sing 'I bought a pair of trousers for John and for Mary.'

(Grillia 2004) 


\section{b. STO YANI agorasa padeloni. to-acc John-acc bought-1sg trousers-acc-sing 'I bought a pair of trousers for John.'}

(Grillia 2004)

As a result, she claims that (15b) is not among the logical entailments of (14a) and therefore that ex-situ focus is always identificational. However, Grillia (2004) successfully shows that Baltazani's (1999) conclusions need to be rethought, based on the observation that the above claim holds only if the predicate is interpreted collectively. According to Grillia's tests, (15a) is ambiguous in that it carries both a collective and a distributive reading. That is, when the predicate gets the distributive reading, (14b) is among the logical entailments of (15a). In that case, ex-situ focus is not identificational. As a result, the ambiguity present in cases like (15) makes the judgements inconclusive with respect to the relation between ex-situ focus and exhaustive interpretation. So, the picture is not so clear after all, with the presence of a collective reading weakening the connection between a particular kind of focus and a particular interpretation. Grillia (2004) thus decides to control for 'collectivity' using (i) an overt distributive marker and (ii) a plural. The test is modified in the following way:

(16) a. Sto YANi Ke STI MARia Agorasa apo ena padeloni. $\rightarrow$ to-the John and to-theMary bought-1sg eachone-acc trousers-acc-sing 'I bought for John and Mary a pair of trousers each'

b. Sto YANI agorasa padeloni to-acc John-acc bought-1sg trousers-acc-sing

'I bought a pair of trousers for John'

(16b) is among the logical consequences of (16a), and therefore the ex-situ focus is not identificational. Grillia (2004) also controls for collectivity by using an 'aggressively non-D-linked' wh-question, such as What the hell did you buy for John? for (16b). Thus, Tsimpli (1995) and Baltazani (1999) seem to have incorrectly attributed to the preposed focus phrase in Greek an exhaustive interpretation resembling that of the English cleft construction.

To control for the collective reading found in (17), Grillia (2004) uses a bare plural instead of a definite DP and replaces the singular predicate in (17) with a plural one, as shown in (18) and (19):
Ston Petro danisan to vivlio.
to-the-acc Peter-acc lent-3pl the-acc book-acc
'They lent the book to Peter.'

In this case, (18b) is among the logical consequences of (18a) and the same holds for (19a) and (19b). Not only does the preverbal focus not carry an exhaustive interpretation, but the same focused phrase can also occur in postverbal position with no difference in interpretation: 
(18) a. Ston Petro Ke STON YANI danisan vivlia. $\rightarrow$ to-the-acc Peter-acc and to-the-acc John-acclent-3pl books-acc 'They lent books to Peter and to John'

b. STON PETRO danisan vivlia. to-the-acc Peter-acc lent-3pl books-acc

'They lent books to Peter'
a. Danisan vivlia STON PETRO KE STO $\quad$ YANI. $\rightarrow$ lent-3pl books-acc to-the-acc Peter and to-acc-the-acc John 'They lent books to Peter and John'
b. Danisan vivlia STON PETRO. lent-3pl books-acc to-the-acc Peter 'They lent books to Peter'

What these examples show, then, is that in Greek the ex-situ focus position does not need to receive an exhaustive interpretation. In addition, exhaustivity is susceptible to collectivity, which is not considered by Baltazani (1999) and Tsimpli (1995).

Test B concerns the possibility of negating exhaustivity and information focus. More specifically, in a dialogue pair where the first sentence contains a focus and the second sentence denies the uniqueness of the referent identified by the focus, this focus can only have an exhaustive interpretation. What (20) shows is that in Hungarian exhaustivity can be negated, as shown in (20a, b), but new information focus cannot, as shown in $(20 \mathrm{c}, \mathrm{d})$ :

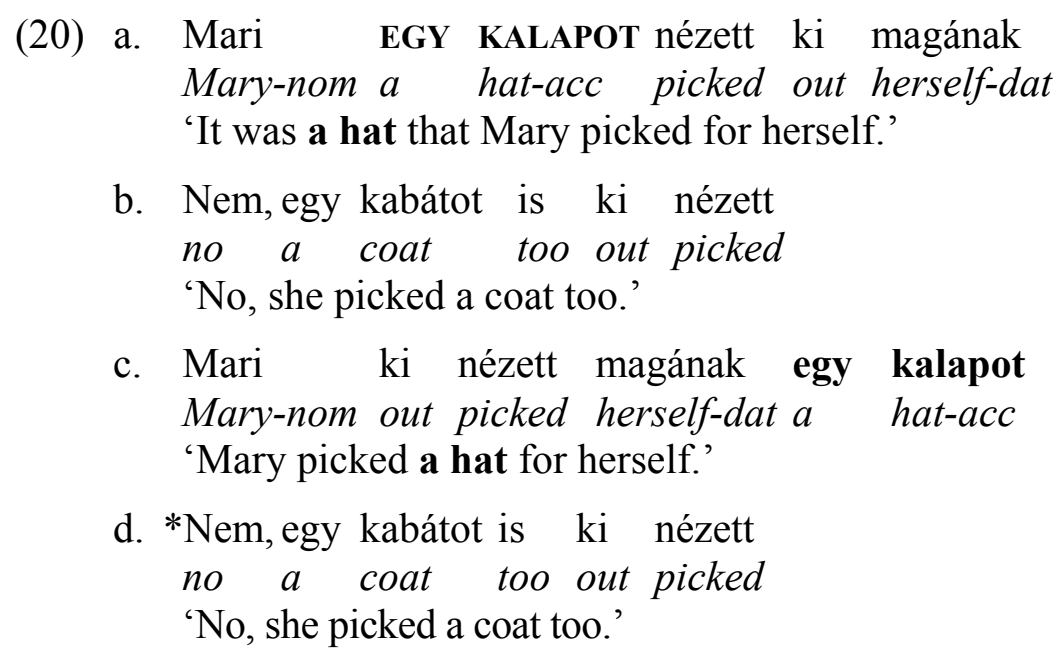

In example (c) the focused object represents the only thing that Mari picked out for herself. In (d), in contrast, it represents one of the possible relevant things that she could have picked for herself; thus the focused object in (d) is new information focus. The ungrammaticality of (d) is obvious because it unnaturally negates the assertion of a proposition where there is a list of possible referents available rather than only one unique referent. Thus, in Hungarian exhaustivity cannot be negated. 
If we apply this test to a Greek example, we can see immediately that there is no direct correlation between ex-situ focus and exhaustive interpretation.

(22) a. ENA KAPELO agorase i Eleni.

a hat-acc bought-3sg the Helen-nom

'Helen bought a hat.'

b. oxi, agorase ke ena pandeloni.

no bought-3sg and a trousers-acc

'No, she bought (this) and a pair of trousers, too.'
a. i Eleni agorase ena kapelo
the Helen-acc bought-3sga hat-acc
'Helen bought a hat.'
b. oxi, agorase ke ena pandeloni.
no bought-3sg and a trousers-acc
'No, she bought (this) and a pair of trousers, too.'

When applied to Greek, then, this test shows that information focus or in-situ focus can also have the exhaustive interpretation. That is, if by negating the proposition that Helen bought a hat for herself, we negate the exhaustive reading of the proposition, then both types of focus can be interpreted exhaustively. Thus, the Greek data show that we can maintain the claim that focus interpretation is independent of syntactic position. Both positions, in-situ and ex-situ, carry the same interpretation. Therefore, the distinction made by É. Kiss (1998) does not hold for the Greek data.

Intuitively, even in the above test the exhaustive interpretation does not seem very salient. That is, it is not clear that the above exchange in (22)-(23) identifies a unique referent or is the result of the semantic function of exclusion of identification, in É. Kiss's terms. I believe that the exhaustive interpretation can be maintained in both syntactic positions if the sentences imply association with focus with the use of an adverb like mono 'only', which inherently carries an exhaustive interpretation. ${ }^{16}$ In such a case, the proposition excludes Helen buying something else besides a hat. Thus, the addition of the adverb meaning 'only' can induce exhaustive identification.
a. i Eleni agorase mono ena kapelo. the Helen-acc bought-3sg only a hat-acc 'Helen only bought a hat.'
b. oxi, agorase ke ena pandeloni.
no bought-3sg and a trousers-acc
'No, she bought (this) and a pair of trousers, too.'

\footnotetext{
${ }^{16}$ For a similar test in Italian, see Brunetti 2003. Brunetti shows, interestingly, that the preverbal focus position is acceptable only if the sentence includes an only-phrase. In this case, the focus can express exhaustive identification.
} 
Test $\mathrm{C}$ shows that identificational focus cannot consist of a universal quantifier, an existential quantifier, an even-phrase, or an also-phrase, but that information focus does not display these distributional restrictions. É. Kiss attributes these restrictions to the semantic content involved in these cases, which are not compatible with the semantic function of exclusion of identification. Interestingly, however, the Greek examples do not show this identification focus/informational focus contrast:

(25) KATHE FITITIS perimeni ta apotelesmata (UNIVERSAL QUANTIFIER) every student-nom wait-3sg the results-acc

'Every student waits for the results'

(26) KAPJA THEMATA tha lithoun avrio (EXISTENTIAL QUANTIFIER) some issues-nom will-fut be solved-3pl tomorrow

'Some issues will be solved tomorrow'

(27) AKомI KaI STIN MaRia edosan vravio (EVEN-PHRASE) even and to-the Maria-accgave-3pl prize-acc 'They gave a prize even to Mary'

(28) KaI LOULOUdia tis agorase tis Elenis o Janis (ALSO-PHRASE) and flowers-acc her-cl bought-3sg the Helen-genthe John-nom 'He bought and flowers for Helen'

As (25)-(26) show, quantifiers can occupy the preverbal position in Greek. Therefore, no restriction with respect to exhaustivity applies: the focus constituent can be any of the quantifier phrases in preverbal position. However, native speakers' opinions are not uniform on the question whether the sentences in (25)-(28) express exhaustive identification. What is most likely is that not all quantifiers in preverbal position have an easily available interpretation as exclusion of identification. However, they definitely carry new-information focus, which is also significant, since a preverbal as well as a postverbal position for the quantifier can be filled by a new-information focus phrase. Especially interesting is the case of the existential quantifier. According to É. Kiss, the existential quantifier in Hungarian is not compatible with new information focus, in particular when found in postverbal position (which is the only position consistent with new-information focus in É. Kiss's terms). However, in Greek, this is not the case, as shown in (29):

(29) Yiati oles autes i etimasies?

'Why all these preparations?'

Perimeno kapjon gia fagito.

Wait-1sg/prog someone for dinner-acc

'I am waiting for someone for dinner.'

The fact that the existential quantifier is odd as new-information focus is due to its limited potential to provide precise information in updating the information status of the utterance. Also, the referential use of an existential 
quantifier is limited to contexts such as questions, which presuppose a referential expression in the answer. Nevertheless, if the quantifier functions as an answer to an all-focus question, given that it becomes more informative, it can also become much more acceptable.

É. Kiss's test D indicates that only identificational focus takes wide scope since only this focus expresses exhaustive identification. This characteristic of exhaustive identification is exactly what makes the focus interact with other scope-carrying elements. For my application of test D to Greek, speakers were presented with examples where the universal quantifier takes scope over focus in-situ (30), and where focus (ex-situ) takes scope over the universal (31).

(30) Kathe sinadelfos ithele me TON DIEUTHINDI na milisi every colleague-nom wanted-3sg with the director-acc to talk-inf 'Every colleague wanted to talk with the director.'

(31) me TON DIEUTHINDI ithele na milisi kathe sinadelfos with the director-acc wanted-3sgto talk-inf every colleague-nom 'Every colleague wanted to talk with the director.'

According to É. Kiss, a similar example in Hungarian would induce two different interpretations. Thus, the Hungarian counterpart of (30) indicates that every colleague wanted to talk with one person, the director, and not with any other relevant person. Thus, the universal quantifier takes scope over the exhaustive identification. On the other hand, the Hungarian counterpart of (31) indicates that the director is the only person all of the colleagues want to talk to and that other people were talked to by a subgroup of colleagues but not all of them. Thus, the exhaustive identification takes scope over the universal quantifier.

In contrast to the situation in Hungarian, native speakers of Greek perceive no difference with respect to the propositional content of the sentences in (30)(31). That is, these sentences both have the same truth value, namely that all the colleagues wanted to talk to the same person and nobody else. Moreover, none of the sentences prohibit the possibility that some colleagues wanted to talk to with some other person apart from the director. Naturally, the focused phrase carries no property of exclusion, therefore no exhaustive interpretation. In this sense, there is no real scope-taking difference with respect to exhaustivity and the universal quantifier. On the contrary, the focused phrase has the properties of an ordinary focused nominal argument, rather than an operator having scope properties. Note, though, that some scope possibilities are manifested when the quantifier mono 'only' is added to the sentence. In this case, the meaning of the examples is similar to the ones in Hungarian: 
(32) UNIVERSAL QUANTIFIER $>>$ EXHAUSTIVE IDENTIFICATION kathe sinadelfos ithele mono me TON DIEUTHINDI na milisi every colleague-nom wanted-3sgonly with the director-acc to talk-inf 'Every colleague wanted to talk only with the director'

(33) EXHAUSTIVE IDENTIFICATION $>>$ UNIVERSAL QUANTIFIER mono me TON DIEUTHINDI ithele na milisi kathe sinadelfos only with the director-acc wanted-3sg to talk-inf every colleague-nom 'Every colleague wanted to talk only with the director'

Thus, the claim that identification focus takes scope relevant to its exhaustive interpretation cannot be maintained for Greek. Another problem appears when considering scope effects. Recall that É. Kiss (1995a, 1995b, 1996) argues that focus-in-situ differs from constructions involving movement in that it is not quantificational. First, it does not change the truth conditions of the sentence; and second, it does not involve (semantic) uniqueness. É. Kiss (1995a, b) illustrates this by comparing cleft sentences with focus-in-situ sentences but the same tests may be applied to the difference between focus-in-situ and focus movement. The crucial tests for identifying the quantificational nature of focus come from Szalbolcsi (1981), who shows that the displaced focus in Hungarian does have quantificational force and does change the truth values of the sentences because it implies uniqueness. However, consider the following examples:

(34) a. Tegnap este MARINAK mutattam be Pérert last night Mary-dat introduced I.Perf Peter-acc 'It was TO MARY that I introduced Peter last night'

b. Tegnap este be mutattam Pétert MARINAK

'Last night I introduced Peter TO MARY'

(É. Kiss 1998, ex. 5)

With respect to interpretation the two cases differ. In (a), the immediately preverbal focus expresses exhaustive identification (in É. Kiss's terms); this sentence indicates that of the set of individuals present in the in the domain of discourse, it was Mary and no one else that I introduced to Peter last night. The postverbal focus in (b), on the other hand, merely represents Mary as presupposed information, without suggesting that Mary was the only one of a set of relevant persons that I introduced Peter to last night (again according to É. Kiss's account of exhaustion of identification).

The truth is that whatever the interpretative differences between (a) and (b), there is no difference in the truth conditions of these sentences. The fact that distinct structural positions are involved and that these examples are not simply two optionally available variants does not mean that there is a difference in their propositional content (cf. Alexopoulou 1999). According to Krifka (1992) and Vallduvi (1992), identificational foci assimilate to informational foci; they both have the same semantic structure, since in 
general focusing of a constituent does not add to the semantic content of the sentence; it figures only in its information structure. This is very important in arguing for the dissociation of information structure from semantics. Krifka (1992) further assumes that the difference between these sentences lies only in the illocutionary operator that binds them. The same phenomenon is attested in Greek Topicalization/CLLD.

(35) a. amfivalo oti klidose TIN PORTA doubt-1sg that locked-3sg the door-acc

'I doubt that (he) locked the door.'

b. tin porta amfivalo oti tin KLIDOSE the door-accdoubt-1sg that it-cl locked-3sg

'The door, I doubt that (he) locked it.'

Here, again, the two constructions differ in their interpretations, but this difference does not affect their propositional content. The lack of a truthconditional difference thus provides further proof of the non-quantificational nature of focus.

\subsection{The PF Interface}

In the previous section, I presented evidence against the standard assumption that there are two semantically unrelated and divergent types of focus in Greek, showing that É. Kiss's (1998) claim does not hold for the language. The analysis of the relevant evidence provided arguments in favour of the claim that focus is a uniform phenomenon with a uniform interpretation: that is, it always expresses new information. The exhaustive interpretation of focus is not an inherent focus-internal property, specific to focus phenomena, but turns out to be the outcome of the interaction between the semantic component and the discourse component, i.e. context.

In what follows, I will argue that focus is also one and the same phenomenon with respect to the PF interface. Focus is mainly related to stress in any position it can be spelled out and there are no different stress/accent assignments corresponding to different semantic types of focus.

The fact that the two types of focus are related to two types of prosodic prominence, contrastive and non-contrastive, has been suggested in accounts of the focus-prosody relation in Germanic languages like English, German and Dutch, particularly within the argument structural (AS) approach to focus structure (Gussenhoven 1984, 1992; Rochemont 1986; Schmerling 1976; Selkirk 1984, 1995). More importantly, though, as has been generally claimed for Romance languages, stress is determined by some version of the Nuclear Stress Rule (NSR), as in work by Cinque (1993) and Zubizarreta (1998) (see also Donati \& Nespor 2003; Ladd 1996 for Italian; Costa 1998; Frota 1998 for European Portuguese;). In the latter approaches, the claim that there are two 
types of prominence, emphatic and non-emphatic, with two distinct corresponding interpretations has played a central role.

More recently, Donati \& Nespor (2003), along the lines of É. Kiss (1998), claim that Focus with an emphatic or contrastive interpretation cannot project in Italian and that 'neutral' prominence associated with Focus always has to be larger than a single word. In addition, Zubizarreta (1998) proposes an extra phonological rule, the Emphatic/Contrastive Rule (E/CSR), to account for focal stress related with a contrastive/emphatic focus interpretation.

In the rest of the section, I will look at Zubizarreta's (1998) account and provide arguments against the E/CSR. Zubizarreta (1998) allows for two types of focus: informational focus and contrastive focus (i-focus and c-focus, respectively).

(36) a. Q. C'est qui qui a écrit un livre sur les rats? It is who that wrote a book about rats?'

A. C'est [DP le chat] qui écrit un livre sur les rats.

'It is the cat that wrote a book about rats.'

b. Q. C'est quoi que le chat a écrit?

'It is what that the cat wrote?'

A. C'est [DP un livre sur les rats] que le chat a écrit. 'It is a book about rats that the cat wrote.'

The property of exhaustivity distinguishes the two types of focus. I-focus is non-exhaustive and c-focus is exhaustive.

(37) a. Q. Who wrote a book about rats?

A. [DP The cat] wrote a book about rats, and [DP the bat] did too.

b. Q. C'est qui qui a écrit un livre sur les rats?

'It is who that wrote a book about rats?'

c. *C'est [DP le chat] qui a écrit un livre sure les rats, et aussi

[DP la chauve-souris]

'It is the cat that wrote a book about rats, and also the bat.'

$\mathrm{C}$-focus involves an independent emphatic/contrastive phrasal stress rule that places main prominence on the c-focus constituent; this rule identifies c-focus as well as allowing metalinguistic functions such as correction, as in I said Confirmation, not affirmation. Contrastive stress can surface on function words, such as the do-form in John DID leave. It is always associated with an audibly higher pitch level and is strictly narrow in scope, as in The cat in the [ADJ BLUE] hat wrote a book about rats (not the one in the red hat).

I-focus is identified as the result of the prominence assigned by the Nuclear Stress Rule (NSR). NSR assigns main prominence within the focus structure of the phrase. Moreover, function words are invisible for the computation of the NSR: nuclear stress (NS) never surfaces on a function word. Thus, c-focus may be applied anywhere including on functional words, but i-focus involves 
a NSR that applies NS. The latter is due to a well-formedness condition and occurs at a point prior to LF.

Zubizarreta argues that the position of NS in Germanic languages is a result of the interplay of two rules, one sensitive to selectional ordering and one sensitive to ordering defined in terms of asymmetric c-command. In both, the 'lowest' constituent receives the NS under different dimensions, as shown in (38)-(39).

(38) S-NSR: Given two sister categories $\mathrm{Ci}$ and $\mathrm{Cj}$, if $\mathrm{Ci}$ and $\mathrm{Cj}$ are selectionally ordered, the one lower in the selectional ordering is more prominent.

(39) C-NSR: Given two sister categories $\mathrm{Ci}$ and $\mathrm{Cj}$, the one lower in the asymmetric c-command ordering (as defined in Kayne 1994)is more prominent.

Only the C-SNR is available in Romance languages, subject to parametrization.

(40) a. Un nino ha bailado

A boy has danced

(Spanish)

b. Un nino ha bailado

(41) a. Un garcon a dansé

(French)

b. Un garcón a dansé

(examples from Zubizarreta 1998)

In German, English and French, defocalised and anaphoric constituents are 'metrically invisible' with respect to the NSR. However, in Spanish and Italian, all phonologically specified constituents are 'metrically visible'. Main prominence on phrase-internal constituents may be associated with a noncontrastive focus interpretation in Germanic:

(42) Jóhn ate the apple

[Who ate the apple?]

In contrast, in Spanish and Italian, the interpretation is contrastive or emphatic, and therefore not compatible with a focus neutral interpretation.

(43) *Juan comio una manzana

Juan ate an apple

(44) [Who ate the apple?]

(45) JUAN comom una manzana ( non Piero).

(46) * Maria puso el libro sobre la mesa

Maria put the book on the table.

What did Maria put on the table?]

(47) Maria puso el LIBRO sobre la mesa (no la revista)

Maria put the book on the table not the journal. 
(48) *Maria lee (vs Maria lee)

* Maria baila (vs Maria baila)

* Maria voto (vs Maria voto)

(49) J'ai un probleme à resoudre. (* un probleme à resoudre)

'I have a problem to solve.'

(Zubizarreta 1998)

The difference is that all phonological material is metrically visible in Romance and as result not skipped by the NSR. Therefore, the direct relation between focus and stress is always achieved in the most embedded position of the clause. In cases where the focused element appears in a position different from the NS position (phrase-internal or -initial), stress is assigned via the $\mathrm{E} / \mathrm{CSR}$, as given in (52). The position of NS is unambiguously at the end of the sentence (or phrase), but the scope of contrastive focus in phrase-internal cases is identified by the E/CSR. Thus, sentences with main prominence on the preverbal subject in Spanish, as in (50)-(51), receive stress via the E/CSR rather than by the NSR, and can only have a contrastive focus interpretation on the preverbal subject, e.g. Juan and Maria.

(50) a. JUAN llamo por telefono (no Pedro) Juan phoned (not Pedro)

(51) b. MARIA se comio el pastel (no Marta) Maria ate the cake (not Marta)

(Zubizarreta 1998)

(52) Focus/Contrastive Stress Correspondence PRINCIPLE (E/CSR): A word with contrastive stress must be dominated by every F-marked constituent in the phrase.

If we can show that information focus can occupy any higher position in the clause (phrase-internal, left-peripheral), then the E/CSR in (52) fails to maintain its idiosyncratic nature. In this case, we could dispense with Zubizarreta's extra metalinguistic use of the E/CSR and assimilate it to one rule, the NSR, which reintegrates all the different interpretational functions.

According to (52), the element that bears the stress of the sentence must be dominated by any focused part of the sentence. Zubizarreta offers the following examples as support for the E/CSR. In (53), with contrastive stress on the adjective, either the adjective or a constituent that exhaustively dominates the adjective may constitute the scope of the contrast. In (54), with contrastive stress on the noun, the scope of contrast is limited to the noun. In effect, the DP that contains the contrastively stressed noun cannot be interpreted as focused, because the DP is marked [F]. So is the PP that it dominates, but the contrastively stressed noun does not dominate the PP. Thus, $[+\mathrm{F}]$-marked constituents may only dominate $[+\mathrm{F}]$-marked constituents. 
(53) a. El gato de sombrero $\{\mathrm{ROJO}\}$ escribio un libro sobre ratones the cat of hat red wrote a book about rats (no el sobrero azul). (not that of the hat blue).

'The cat with a red hat wrote a book about rats (not the one with a blue hat).'

b. $\{$ El gato de sombrero $\mathrm{ROJO}\}$ escribio un libro sobre ratones

the cat of hat red wrote a book about rats

(no el perro de chaqueta VERDE).

(not the dog of the jacket green)

'The cat with a red hat wrote a book about rats (not the dog with a green jacket),'

(54) a. El $\{$ GATO $\}$ de sombrero rojo escribio un libro sobre ratones

the cat of hat red wrote a book about rats

(no el PERRO de sobrero rojo).

(not the dog of the hat red)

"The cat with a red hat wrote a book about rats (not the dog with a red hat)"

b. ${ }^{*}$ El $\{$ GATO de sombrero rojo\} escribio un libro sobre ratones (no el PERRO de chaqueta verde).

(Zubizarreta 1998)

What seems to be important in the two sets of examples is that in accordance with the E/CSR, stress must always coincide with the most embedded constituent of the focused phrase. In effect, every word that is F-marked dominates the stressed constituent as of that position. Thus, the only difference in the requirements between the NSR and the E/CSR is that in the former, main stress must coincide with the most embedded constituent of the clause in Romance, whereas in the latter, contrastive/emphatic stress must fall on the most embedded constituent of the focused phrase. The Greek word order examples given in section 4 clearly established that stress assigned to the focused element does not always have to be rightward or the most embedded in a clause. What is required is that the stress indication of focus must be as far right as possible within the phrase that contains it. In this respect, it can freely occupy any position in the clause, as long as it falls on the most embedded element in the phrase carrying the focus.

Given this, there seems no need to postulate another rule to account for the metalinguistic interpretational/contextual effects of focus. E/CSR is conceptually and empirically redundant, since it derives exactly the same result as the NSR. Stress-inducing focus (c-focus or i-focus) is assigned by the NSR to the rightmost constituent of the phrase containing it, regardless of the position of the phrase in the clause. As such, the realization of focus by prosodic means is independent of the syntax of focus. 
There is an additional challenging inconsistency in the nature of the $\mathrm{E} / \mathrm{CSR}$, one concerning its relation to stress-driven (or in Zubizarreta's terms prosodically driven) movement, as mentioned in section 2 .

In line with Cinque (1993), Zubizarreta assumes a Focus-Prominence Rule (FPR), given in (55), that regulates the relation between prosody and focus. The FPR states that between two sister categories, one focused and the other non-focused, the first must be more prominent than the second.

(55) Focus PROMINENCE RULE: The F-Structure of the sentence is constrained by the location of main phrasal prominence: Given two sister categories $\mathrm{Ci}($ marked $[+\mathrm{F}]$ ) and $\mathrm{Cj}($ marked $[-\mathrm{F}]$ ), $\mathrm{Ci}$ is more prominent than $\mathrm{Cj}$.

Recall that the modularized version of the NSR (extending Cinque's NS account) explains the differences between Germanic and Romance. Now, in certain cases both the FPR, as given in (55), and the C-NSR, given in (39) for Romance, apply, yielding conflicting outputs. The former requires a direct mapping between stress and focus and the latter assigns stress to the most deeply embedded constituent. In Germanic languages the grammar resolves this conflict by considering 'defocalized' constituents as metrically invisible, as stated above. However, in Romance, where there is no metrical invisibility, the conflict is resolved by allowing for 'defocalized' material to undergo movement, so that the focused material in the most embedded position receives stress according to the NSR. This is what Zubizarreta calls prosodically-driven movement or p-movement, since this movement satisfies PF interpretations. Moreover, the focused constituent first moves to the specifier of FocusP, a pre-verbal position in the left periphery. This allows for a remnant type of p-movement of defocalized material — that is, movement of a phrase that includes the trace of a previously removed constituent - to an even higher position. This permits a successful mapping between focus and main prominence, placing focus where stress falls, in the most embedded position.

Nevertheless, focus in the most embedded or clause-final position can certainly be contrastive, as shown in section 4 for Greek and illustrated in (56) below, which provides a VOS structure:
a. [[тp tin askisi tin elise] [Fp I MARIA]] (oxi i Eleni) the exercise-acc it-cl solved-3sg Maria-nom (not Helen)
b. [[тр to fagito efage [o Costas]] (oxi o Yannis). the food-acc ate-3sg Costas-nom (not Yannis)

If we followed Zubizarreta, we would have to take the focused item in (56) to be assigned stress by the E/CSR. But why should this item stay in final position, if it can be assigned stress by the E/CSR in the preverbal or medial position (actually the default case for contrastive stress)? There is no need for 
the focused item to occupy the clause-final position and for the remnant TP material above it to be p-moved if stress can apply in clause-initial position. The question is: given the existence of the E/CSR, why resort to 'costly' operations that violate economy considerations? If the E/CSR applies consistently every time contrastive focus is relevant, then p-movement loses its empirical motivation. To allow for p-movement to operate in cases such as (56) would mean that that E/CSR does not apply uniformly to all cases of contrastive focus.

The above considerations indicate that one of the two prosodic operations, application of E/CSR or syntactic p-movement, needs to be eliminated, since having both operations is empirically and theoretically superfluous. I will dispense with the $\mathrm{E} / \mathrm{CSR}$, since it accounts for a situation similar to information focus, involving the application of information focus to other than clause-final positions. The amalgamation of the two rules is clearly consistent with the argument presented in previous sections, namely that an interpretive difference between the two foci cannot be maintained.

To summarize this section and the previous one, I have discussed the properties of focus with respect to the interfaces, LF and PF, and shown that there are not two different types of focus from interpretive and prosodic perspectives. Rather, focus is a single phenomenon in the syntax and at both interfaces. In the next and final section, I will propose a syntax-prosody mapping to account for the Greek data in section 4.

\section{The Syntax-Prosody Interface}

As mentioned in section 1, I adopt the position of Chen (1987), Nespor \& Vogel (1986), Zec \& Inkelas (1990) and Jackendoff (1997), among others, that the grammar represents syntactic and phonological-prosodic information in two distinct levels of representation.

The rules of phonology proper (i.e. rules that govern phonological patterning, including rules of stress assignment) do not refer directly to syntactic constituents but rather operate on the prosodic structure and, more precisely, on the units of the Prosodic Hierarchy (see Chen 1987; Nespor \& Vogel 1986; Selkirk 1984, 1986). Thus, the prosodic representation is not derived directly and unambiguously from the syntax, as it is in Minimalism. ${ }^{17}$ In other words, phonological rules apply to units of the Prosodic Hierarchy in the prosodic domain, these units not always structurally isomorphic to syntactic representations. Focus is not always rightmost but only as far right as

${ }^{17}$ This approach goes against Cinque's (1993) stress-based account and accounts such as those of Zubizarreta $(1994,1998)$ and Reinhart (1995), who claim a syntax-based NSR. However, it agrees with stress-based theoretical accounts such as Szendröi's (2001). 
possible, and so is stress. Thus syntactic and prosodic representations are related by mapping rules that group the terminal elements in a string in a way that creates units which are not in one-to-one relation with the constituents of the syntactic hierarchy. Prosodic units are created by means of a mapping algorithm - that is, a set of rules that determine the type of information accessible from one grammatical module to another. Consequently, the phonological feature sets of lexical items are grouped into prosodic structure: forming prosodic words $(\omega)$, which in turn form phonological phrases $(\varphi)$, which in turn are grouped intonational phrasse (IntPs) (see Nespor \& Vogel 1986). ${ }^{18}$

Selkirk's mapping algorithms are basic to an analysis where phrase-edge prominence plays a crucial role. I will follow Selkirk (1986) in assuming the following mapping procedure in (57) for phonological phrase, or p-phrase $(\varphi)$, formation (also adopted in Neeleman \& Reinhart 1998):

(57) $\Phi-F O R M A T I O N$

Close $\varphi$ when encountering] XP

The procedure in (57) has the effect that the right edges of phonological phrases coincide with the right edges of syntactic phrases. Selkirk (1995) claims that there is a predisposition towards lexical categories. More specifically, Selkirk proposes that only lexical categories and their projections, and not functional ones, are visible to the mapping rules. There is considerable empirical evidence in support of such a restriction, which complements Nespor \& Vogel's (1986) non-visibility of empty categories and their projections. Prosodic constraints refer to lexical elements $\left(\mathrm{L}^{0}\right.$ elements and their projections, $\left.\mathrm{L}^{\max }\right)$ but not to functional elements $\left(\mathrm{F}^{0}\right.$ elements and their projections, $\mathrm{F}^{\max }$ ) nor to empty categories and their projections, in accordance with the Lexical Category Condition (LCC) of Truckenbrodt (1999: 226). ${ }^{19}$

In Optimality Theory (e.g., McCarthy \& Prince 1993; Prince \& Smolensky 1993), edge-based rules have been converted into McCarthy \& Prince's (1993) Generalized Alignment constraint system. Each alignment constraint represents a requirement on the matching of morphosyntactic with prosodic edges. Selkirk (1995) has proposed the following constraints on edgealignment of syntactic phrases with phonological phrases:

\footnotetext{
${ }^{18}$ The status of the p-phrase as the most important part of prosodic constituent structure is well established in the linguistic literature (see, e.g., Hayes 1989; Nespor \& Vogel 1982, 1986; Selkirk 1978, 1981, 1986, 1990). The p-phrase is the principal constituent mediating between syntactic structure and prosodic form. The task of showing how syntax interfaces with phonological structure is quite complicated and is usually undertaken by the construction of the mapping algorithms.

${ }^{19}$ This later condition includes Selkirk's Categorical Invisibility of Function Words (1984: 337 ), and emphasizes the invisibility of function words with respect to the application of the prosodic algorithms.
} 
(58) EDGE-ALIGNMENT CONSTRAINTS:

a. Align-XP,L: Align (XP, L; PPh, L)

'For each XP, there is a $\mathrm{PPh}$ such that the left edge of XP coincides with the left edge of $\mathrm{PPh}$.'

b. Align-XP,R: Align (XP, R; PPh, R)

'For each XP, there is a PPh such that the right edge of XP coincides with the right edge of $\mathrm{PPh}$.

Truckenbrodt $(1995,1999)$ has offered a convincing argument for the necessity of including a cohesional constraint WRAP-XP, stated in (59), in the family of interface constraints. In many languages, a major syntactic phrase preserves its integrity and is mapped into a single p-phrase. In accordance with the LCC, the constraint penalizes separate phrasing of lexical projections but, interestingly, permits the split up of functional ones. His argument builds on the phrasing differences of three Bantu languages.

(59) WRAP-XP: Each XP is contained in a phonological phrase. ${ }^{20}$

I thus follow Selkirk and Truckenbrodt $(1995,1999)$ in maintaining the idea that syntactic structure is parsed into prosodic constituents and that the heads of these constituents in turn determine the rhythmic grid eventually responsible for the position of main stress. Once the mapping rules are applied, syntactic structures can no longer be used to condition phonological rules. The theory thus predicts that two sentences with same linear sequence of lexical elements but different syntactic structures will be ambiguous if their prosodic structures are equal (cf. Nespor 1993, 1996). Non-isomorphism between syntactic and phonological structures is thus established.

\subsection{Aligned versus Misaligned Mapping}

Assuming the framework introduced above, I propose that two types of rules are operational in the mapping process: default alignment rules and focusrelated rules. The former are responsible for the assignment of main stress in the unmarked cases and the identification of the sentence's focus. The latter identify focus positions other than clause-final ones - for example, phrase-

\footnotetext{
${ }^{20}$ An abstract example will clarify how exactly the end-based algorithm applies. Assume a syntactic string like the one in (i). The p-boundaries below the string denote the results of the application of ALIGN-XP,L (1a), ALIGN-XP,R (1b) and WRAP-XP (2c). Differences in phrasing across languages result from different ranking of the relevant constraints.
}

(i) $\quad[\mathrm{V} \mathrm{NP} \mathrm{PP}]_{\mathrm{VP}}$ syntactic string
a. [ ] [ ] [ ] phrasing due to ALIGN-XP,L
b. [ ] [ ] phrasing due to ALIGN-XP,R
c. [ ] phrasing due to WRAP-XP 
internal or left-peripheral - and in the case of stress assignment, they result in a misalignment between syntax and phonology. Therefore, according to the two types of mapping strategies the two representations, syntactic and prosodic, may be either aligned or misaligned. The mapping process will decide and constrain which syntactic trees can be successfully mapped to a given prosodic tree and vice versa.

In the unmarked cases, which I will call Syntax-Prosody Matching or Alignment (henceforth, SPA), a well-formed syntactic representation can be paired up with a well-formed prosodic representation in a way that the syntaxprosody mapping is completely satisfied. This is the case where the right edge of prosody meets the right edge of syntax, where NSR is applied to the most embedded syntactic constituent.

In cases where an element other that the most embedded in the syntactic structure is to be focused, a misaligned mapping is performed to ensure that the element in question appears at the relevant edge of the phonological domain to receive main stress. I will call these cases Syntax-Prosody Mismatch or Misalignment (henceforth, SPM). The relation between the syntactic and the prosodic structure can be altered in such a way so that the focused constituent closes off the right edge of a phonological phrase (or inserts a left boundary, subject to parametrization) other than the one that is final in the clause. The postfocal phonological phrases are integrated into the larger phonological or intonational phrase corresponding to the clause.

This mapping reflects the view that the position of focus is prosodically determined - also the main insight of syntax-based prosodic accounts developed by Cinque (1993), Reinhart (1995) and Zubizarreta (1994, 1998). The same structures, however, show that the main stress is not always rightmost but only as far right as possible, the result of the misalignment process. This is one of the advantages of the proposed mapping, since it immediately captures the above generalization. Such a generalization is nevertheless problematic for syntactic approaches to stress under parametric analyses, so it offers a serious challenge to them. ${ }^{21}$

\footnotetext{
${ }^{21}$ Any syntax-based approach that determines nuclear stress has the serious drawback of requiring the identification of the position of stress earlier than the syntactic operations responsible for stranding focus in the position of stress. In this way, they have no choice but to refer to a syntactic definition of main stress determined in a cyclical fashion until focus and stress are matched in the same position. In contrast, in the mapping operation proposed here, the syntactic and prosodic components are assessed simultaneously and the mapping rules will allow for the acceptable structures provided that the combination of syntactic and prosodic representations will satisfy these mapping rules. For instance, in cases of stringmiddle focus construction, it will not matter for the prosodic operation of stress assignment that the element is not the rightmost within the syntactic structure, as the grammar has two distinct prosodic and syntactic representations.
} 


\subsubsection{The SPA of the Right Periphery}

Recall that in section 6.1, I illustrated the three modules of the grammar that are responsible for a particular focus interpretation of an utterance: syntax, prosody and the syntax-prosody mapping. Syntax in the unmarked case contains no extra operations apart from merge and feature-driven movement (for EPP satisfaction, see Sifaki 2003). As for the syntax-prosody mapping, I assume, following Selkirk (1986), that it applies in the following manner (see also Inkelas \& Zec 1995; Neeleman \& Weerman 1999; Nespor \& Vogel 1986; Szendröi 2001; Truckenbrodt 1999).

In particular, I propose that the mapping between syntactic and phonological phrases is subject to the Default Alignment Mapping Rule given in (60).

(60) SYNTAX-PROSODY MAPPING OF PHRASES (GREEK):

Align the right edge of a syntactic phrase with the right edge of the phonological phrase.

On the level of the clause and the intonational phrase, the following principle is operative in Greek:

(61) SYNTAX-PROSODY MAPPING OF CLAUSES (GREEK):

Align the right edge of the IP with the right edge of the intonational phrase corresponding to that IP.

Principles (60) and (61) capture the case of unmarked right-peripheral information focus, which has been claimed to occur as the most embedded constituent of any XP according to phrasal metrical rules (Cinque 1993; Zubizarreta 1998).

As far as prosodic phonology is concerned, nuclear stress in Greek is assigned as follows:

(62) NSR (GREEK):

Assign main stress on the phonological word in the rightmost phonological phrase of the intonational phrase.

Under wide focus, the rightmost p-phrase within the IP is the intonationally most prominent and receives main stress.

A formulation of the Greek nuclear stress rule is given in $(63):^{22}$

\footnotetext{
${ }^{22}$ In the diagram in (65), I use a metrical tree notation (see Liberman 1979 and Liberman \& Prince 1977). Metrical trees are annotated as Strong (S) or Weak (W). S is assigned to the top node. The main stress falls on the node that is only dominated by S-s, which is indicated in bold.
} 
(63) STRESS RULE (GREEK):

Assign a Strong label to the rightmost phonological word in the phonological phrase. Otherwise assign Weak.

Assign a Strong label to the rightmost phonological phrase in the intonational phrase. Otherwise assign Weak.

Assign a Strong label to the highest intonational phrase.

Let me start by illustrating the application of syntax-prosody mapping together with the stress assignment rules with the example in (64a) and the focus set in (64b).

(64) a. [F pire tilefono o Yanis [F ti MARIA] ke tis ipe... [Ftook-3sg phone the Yanis-nom the Maria-acc] and her-CL told-3sg

b. Focus set: $\left\{\mathrm{DP}_{\mathrm{DO}}, \mathrm{VP}, \mathrm{IP}\right\}$

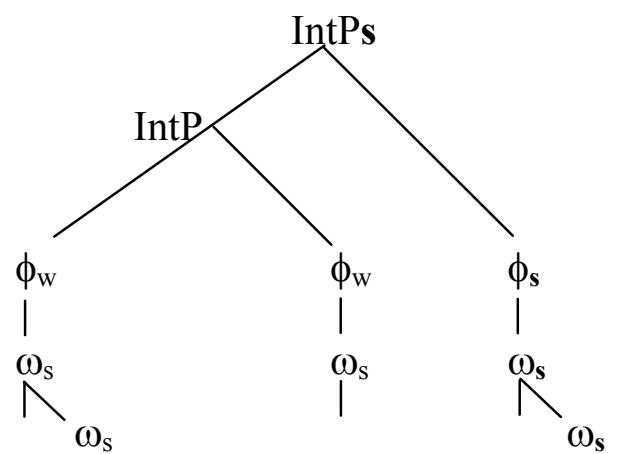

[IP pire tilefono [VP[DP o Yanis [DP ti MARIA]]]]

The unmarked mapping and prosodic rules derive the representation in (65) from the sentence in (64). Relevant to these rules is the fact that in (64), $M A R I A$ is the rightmost syntactically most embedded constituent and the rightmost phonological word in the rightmost phonological phrase. Therefore in the unmarked case (64), the right edge of the intonational phrase is aligned with the right edge of the clause. Given the NSR in (62), MARIA will receive main stress. Therefore at the clausal level of (64), nuclear stress and phrasal stress occur together on MARIA according to the mapping principles (60) and (61). That is, nuclear stress in Greek is assigned to the rightmost phonological phrase in the intonational phrase, according to (61), while phrasal stress is assigned to the rightmost phonological word in the phonological phrase, according to (60). Given the stress-focus correspondence and focus ambiguity facts, we predict that (64) has the focus set indicated in (64b): $\left\{\mathrm{DP}_{\mathrm{DO}}, \mathrm{VP}, \mathrm{IP}\right\}$. We also predict that directly relating LF and PF will allow a direct connection between stress assigned by the NSR and the $[+\mathrm{F}]$ feature which identifies the focused constituent as the legitimate recipient of stress. Thus, the proposed syntax-prosody mapping rules and the NSR derive the fact that an utterance with unmarked intonation may take wide scope by having different possible focus readings. 
To summarize: in this section I have accounted for the right-peripheral focus construction in Greek. These are by definition the default cases, as stress is assigned to the rightmost constituent in Greek in the unmarked case. The model proposed here consists of a mapping operation between syntax and prosody, which is revealed as the domain of application for the default alignment mapping rules. The match is direct and creates no complications, since it is one-to-one, the prosody being the image of syntax. However, the interpretations we derive from the default alignment mapping are many-tomany, since, as we have seen, right-peripheral focus is broad and projects (cf. SVO structure). Thus, a particular utterance carrying right-peripheral focus, under a different context question and with a given intonation, may have more than one interpretation, with more than one possible focus, the focus set of the utterance (in Reinhartian terms).

In the next sections, we will look more closely at clause-internal and leftperipheral focus constructions in Greek. As argued in section 5, these focus constructions are of particular interest, since even though they have narrow scope, they do not necessarily show any semantic distinction between contrastiveness and exhaustiveness.

\subsubsection{The SPM of Middle Focus}

In this section, I will explore the cases of clause-peripheral internal focus constructions. As previously mentioned, these cases are particularly interesting in Greek because, as in the case of right-peripheral focus, the same focused constituent can appear in a string-medial position with no difference in interpretation. Relevant to these cases is the following hypothesis regarding the syntax-semantics interface related to focus.

(66) SyntaX-SEmantics of Focus Hypothesis

Each focus interpretation of a particular utterance included in the focus set which is implemented by a wh-question can be satisfied by a number of word order variations (as shown above), where the same focused constituent can be found in different spell-out positions with the same interpretation.

The identification of the clause-internal focus constructions by the syntaxprosody interface is achieved by a special syntax-prosody misaligned mapping, via the misalignment of focus-related mapping rules. Given that the present analysis makes use of interpretative rules that do not directly refer to syntactic structure, such an analysis of clause-internal focus becomes possible. As we saw above, in the unmarked right-peripheral construction, the right edge of prosody meets the right edge of syntax.

In cases where an element other that the most embedded in the syntactic structure is to be focused, the right edge of the intonational phrase cannot meet the right edge of the clause. This is true of clause-internal focus material. How can we then resolve the conflict between syntax and prosody? In other words, 
how can we avoid the conflict between the Focus-Prosody interaction, which requires the focused constituent of a phrase to contain the intonational nucleus of that phrase, found in sentence-medial position, and the NSR, which assigns stress to the most deeply embedded constituent in the clause? This calls for a misaligned syntax-prosody mapping to ensure that the element in question appears at the relevant edge of the phonological domain to receive main stress.

\subsubsection{Clause-internal Focus and Misalignment}

We know that main phrasal stress plays a crucial role in identifying the intonational nucleus of the intonational phrase (or I-phrase), and that the intonational nucleus is the centre around which the intonational contour is organized. Studies that assume the classic NSR, as well as some of those that have attempted to revise it (e.g. Cinque 1993; Zubizarreta 1998), have recognized that syntactic information plays a crucial role in the computation of main phrasal prominence (and therefore of the intonational nucleus) in the Germanic and Romance languages. But this does not seem to be universally true, as this work has revealed.

In Greek, as in Germanic and Romance, the locus of NS plays a role in determining the possible scope of the focus. However, as shown so far (section 4), syntax cannot play any direct role in the computation of NS and therefore of the intonational nucleus. Instead, NS in Greek is computed in terms of phrasing and, more specifically, the syntax-prosody mapping, which itself is constrained by the syntax.

This has a further theoretical consequence for Greek. If syntax cannot play a role in the computation of NS then hypothesis (66) - namely, that the same clause-internal focus constituent can carry the same semantic interpretation in any other position, right- or left-peripheral - clearly holds. Since syntax is not involved in grammatically encoding focus by the computation of NS but rather that it is prosody, and more specifically the syntax-prosody mapping, that is involved, then the conclusion is that there will be no predetermined syntactic position for focus in Greek.

Returning now to the analysis of sentence-medial focus constructions, with respect to the mapping between syntax and prosody, we can identify the following phrasal stress rules for Greek:

(67) GReEK P-PHRASE StRESS RUle:

Within the P-phrase, the leftmost non-clitic word is prosodically the most prominent carrying the intonational nucleus of the phrase.

(68) Greek I-PHRASe Stress RULE:

A P-phrase bearing narrow focus receives the most prominent stress of its IntP. 
Furthermore, as far as prosodic phonology is concerned, the prosodic phrasing domain is defined as follows. ${ }^{23}$

(69) In Greek, a P-phrase boundary must be inserted at the left edge of the focused constituent.

Thus, from the Align (Info, Pcat) family of constraints that Selkirk (1995) proposes in her model of information structure-phonology interface, we can use the constraint ALIGN-Focus, L in (70) to ensure the mapping of some edge of a focus constituent with some edge of a prosodic unit.

(70) Align-Focus, L

Align the left edge of a Focus constituent in information structure with the left edge of a P-phrase in the prosodic structure.

Given (69) and (70), we may offer in place of the NSR the following mapping rule for misaligned or internal focus-related structures:

(71) Misalignment MAPPING NSR (GReek): Within the I-phrase, NS falls on the rightmost intonationally most prominent P-phrase, the left edge of which must be aligned with the left-edge of the focused constituent.

The above rule predicts that in a narrow-focused constituent in clause-medial position, NS will fall within the intonationally most prominent P-phrase of the I-phrase. In such cases, the last phrasal stress will be the strongest. Hence, in cases where the narrow-focused constituent is internal to the I-phrase, the NS will not be rightmost but as far right as possible.

Let us see now how we can apply the above considerations to the clauseinternal focus discussed in this section and represent the misaligned mapping. This is illustrated in the sentence and tree diagram in (72) below.

(72) o Janis esteile STIN MARIA to gramma.

John-nom sent-3sg to Mary-dat theletter-acc

'John sent to Mary the letter.'

${ }^{23}$ The rule in (69) accords with Baltazani's (2002) and Revithiadou's (2003) analyses of prosodic phrasing (sandhi rules) and intonation in Greek. The narrow focus constituent inserts a left $\varphi$-boundary, thus triggering rightward rephrasing of the string, as in (i):

(i) O Fedon baringile [ANGISTRIA] $\varphi$ 'Phaedon ordered hooks.'

In Greek, focus restructuring proceeds to a direction opposite to syntactic recursion (contra Frascarelli 2000; Kanerva 1989, 1990). 


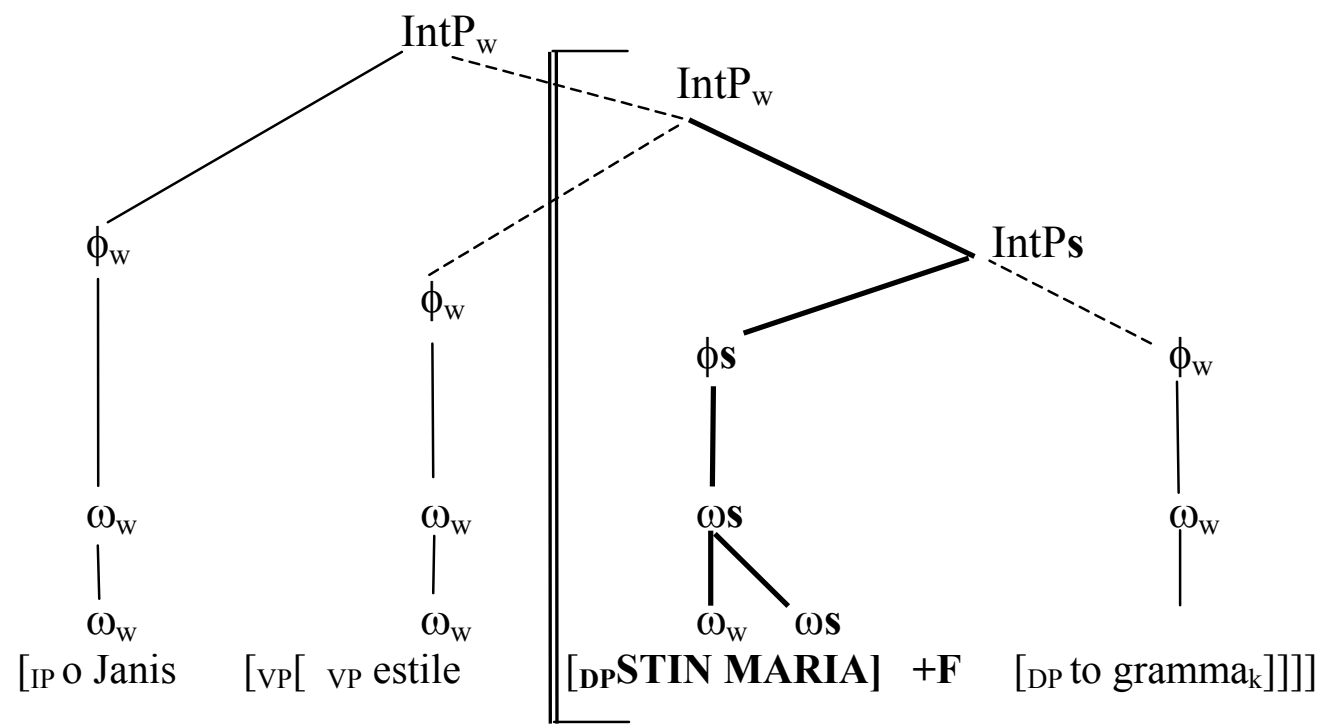

The tree above indicates misalignment between syntactic and prosodic components. According to the misaligned mapping rules, the structure is a narrow focus structure within the I-phrase. Thus, in accordance with Greek Pphrase stress, STIN MARIA is prosodically the strongest phonological word of the phonological phrase it belongs to in virtue of being the rightmost one. Intonationally, the narrow-focused constituent is realized by an intonational boundary taking the form of a $\mathrm{L}+\mathrm{H}^{*}$ nuclear pitch accent (Baltazani 2002), which signals the beginning of a new P-phrase. The following material is deaccented; this material is in turn followed by a LL\% boundary, which closes off the intonational phrase. As regards Greek I-phrase stress, STIN MARIA will bear narrow focus. As a result of the mapping process the intonational boundary on the focus constituent marks its prosodic prominence and as the rightmost intonationally accented constituent it will receive the strongest stress in the intonational phrase.

The P-phrase boundary will be inserted at the left edge of STIN MARIA, which carries the focus. Therefore, the misaligned syntax-prosody mapping process decides that the left edge of the most prominent P-phrase within the Iphrase will coincide with the left edge of the focused constituent. This in turn means that the left edge of the phonological phrase that is inserted when it encounters the focused material will be aligned with the left edge of the syntactic XP that contains that material, in accordance with the mapping rules. The P-phrase boundary defines the domain of the assignment of the NSR. The NS will receive focus since it constitutes intonationally the rightmost P-phrase of the I-phrase. Thus, in cases of where the narrow-focused constituent is internal to the I-phrase, the NS will not be rightmost in the clause. On the 
contrary, it will be rightmost in the phonological phrase that is closed off when it 'reads off' the focus structure.

Assuming a notion of prosodic extrametricality, the material that follows the focused constituent counts as extrametrical; it is part of the phrase containing the focused constituent but is intonationally de-accented. This is also a result of the misaligned mapping process.

It is now apparent how a misaligned syntax-phonology mapping provides a way of focusing a constituent which is not on the right-edge of the utterance: we have to align the left-edge of the phonological/intonational boundary which closes off the focused material with the left edge of the syntactic phrase which contains the constituent to be focused. Given that main stress is assigned to the rightmost element in the prosodic structure, main stress will fall on the focused constituent. It does not matter for the prosodic operation of stress assignment that this element is not the rightmost within the syntactic structure, as the grammar has distinct prosodic and syntactic representations.

\subsubsection{The SPM of the Left Periphery}

Having analysed right-peripheral and clause-internal focus constructions, I will now analyse the last set of focus constructions attested in Greek, the leftperipheral constructions. The following example contains a left-peripheral focus:

(73) Pjon kitakse i Maria?

'Who did Mary look at?'

$\begin{array}{lll}{[\text { F TON YANI }] \text { kitakse }} & \text { i Maria } \\ \text { [F the Yani-ACC] looked-3SG } & \text { the Maria-NOM } \\ \text { 'Maria looked at Yanis.' } & \end{array}$

Given the stress rules in (67) and (68) and the misalignment mapping in (71), I assume that an intonational phrase boundary is introduced before the focused constituent. In the example in (73), the context question indicates that the whole IP except for the focused constituent is given or 'discourse-linked'. The misaligned mapping operation discussed ensures that the focused constituent is at the right edge of its intonational phrase in order to receive stress. Since the focused constituent is a legitimate discourse entity on its own (it can be a sentence fragment), it forms its own intonational phrase. It inserts a leftboundary when focus is introduced in the sentence but it also forms an independent intonational phrase (right boundary) realized as a rising pitch accent $\mathrm{H}^{*}$ followed by a $\mathrm{LL} \%$ boundary tone. Any material that follows will be phonologically unparsed in the Intonational phrase that closes after the focus is encountered and parsed within its own intonational phrase. This makes the postfocal material discourse linked. However, the material that follows is not phonologically de-accented, in contrast to the previous cases 
(clause-internal focus) in section 6.1.2.1, and can therefore form a separate intonational phrase. The misaligned mapping process is illustrated in the following tree: ${ }^{24}$

(74)

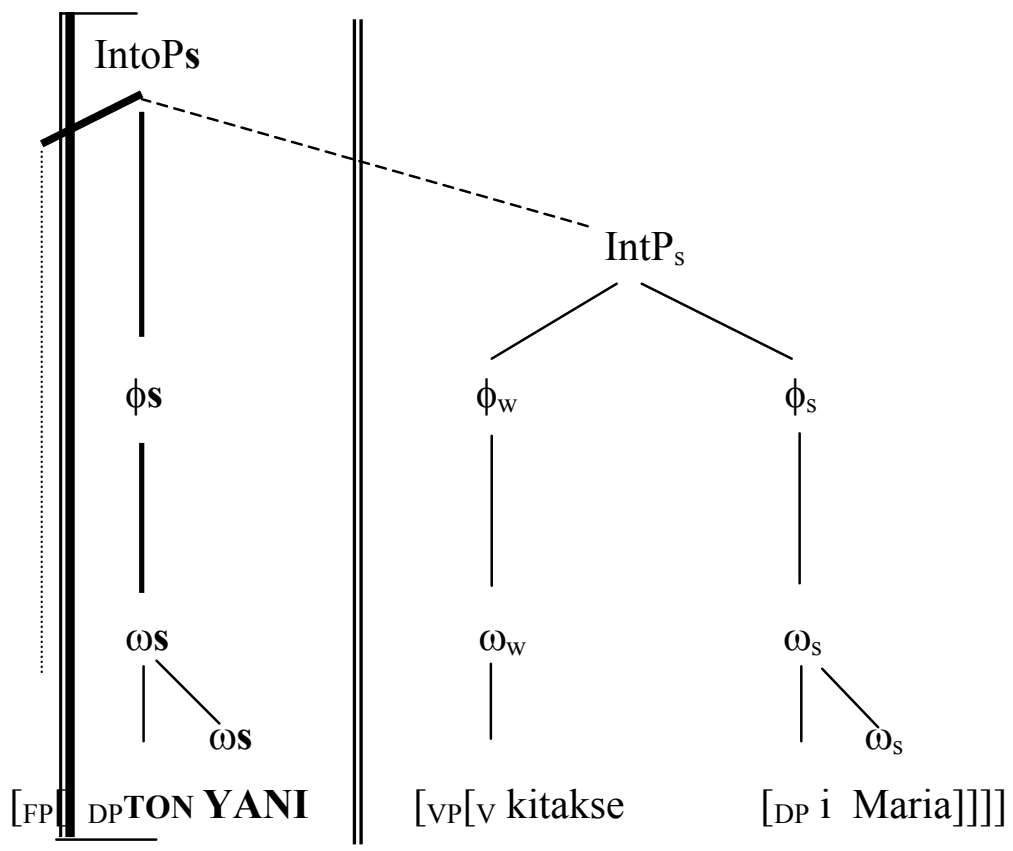

\section{Concluding Remarks}

The present study has sought to challenge the claim that language embraces 'perfection' in arguing against economy considerations as pursued by the Minimalist Program. What I proposed was that the standard Minimalist grammatical architecture has to be modified to allow for both syntactic and prosodic information to access the interface with conceptual structure (C-I) (cf. Reinhart 1995). In other words, the grammar has to reflect the basic intuition that prosodic information has a direct influence on semantics and pragmatics - in particular, that stress $=$ focus. Thus, I argued for a direct interaction between $\mathrm{PF}$ and LF, bypassing syntax, in order to capture the observation that a focused constituent will always carry the main stress.

\footnotetext{
${ }^{24}$ Given that the syntactic and phonological components are distinct and independent, though only linked by a discourse-required special mapping, it is unnecessary for the left-peripheral constituent to be moved by the existence of a focus feature or for the position targeted by movement to be a designated [Spec, Focus] position. The interpretation achieved by the misaligned mapping operation is one of narrow scope but, as indicated in previous discussion, is not necessarily one of contrast or exclusion of identification.
} 
Based on the above assumptions, I proposed that the syntactic, semantic and prosodic representations are independent components of grammar linked by interface mapping processes that access each other simultaneously when necessary (Jackendoff 1997; Williams 2003).

Such a grammatical architecture is forced by the evidence from Greek regarding the interaction of focus with the other components of the grammar. It was shown that in Greek there is no one-to-one mapping between focus position and semantic interpretation. Moreover, it was shown that focus is also a uniform phenomenon at the PF interface. Working in the framework assumed above, I proposed a special type of mapping (SPA and SPM) which accounts for word order variation on the hypothesis that the different spell-out positions of the same focus constituent carry the same interpretation.

I argued that focus is freely assigned via stress and further claimed that focus-markers are syntactically unconstrained and freely assigned. This has the major theoretical consequence: namelym that in a language with no predetermined position for stress there will be no predetermined position for focus. This dispensed with the postulation of unjustified syntactic Focus projections.

The model proposed here is conceptually advantageous since it respects the independence of different levels of representation. No movement for focusinternal reasons is permitted in the syntax in order to derive a consistent set of mapping principles from syntax to phonology/semantics (contra Costa 1996; Choi 1996; Neeleman \& Reinhart 1998; Szendröi 2001; Zubizarreta 1998). On the contrary, the mapping process proposed here straightforwardly predicts that rightmost prominence at the right edges is all that is needed for focus identification.

\section{References}

Abraham, Werner et al., eds. 1986. Topic, Focus and Configurationality. John Benjamins, Amsterdam.

Agouraki, Georgia. 1990. On the Projection of Maximal Categories. UCL Working Papers in Linguistics 2: 182-200.

Agouraki, Georgia. 1993. Spec-Head Licensing: The Scope of the Theory. Ph.D. diss., UCL, London.

Alexiadou, Artemis. 1999. On the Properties of Some Greek Word Order Patterns. In A. Alexiadou, G. Horrocks, and M. Stavrou, eds., Studies in Greek Syntax. Kluwer, Dordrecht, pp. 46-65.

Alexopoulou, Theodora. 1999. The Syntax of Discourse Functions in Greek: A NonConfigurational Approach. Ph.D. diss., University of Edinburgh.

Antinucci, Fransesco \& Guglielmo Cinque. 1977. Sull'ordine delle parole in Italiano: l'emarginazione. Studi di grammatica Italiana 6: 121-146. 
Arvaniti, Amalia \& Mary Baltazani. 2000. Greek ToBI: A System For The Annotation Of Greek Speech Corpora. Proceedings of Second International Conference on Language Resources and Evaluation (LREC2000), Vol. 2: 555-562.

Baltazani, Mary. 1999. Topik and Focus in Greek. Paper presented at the LSA Conference, Los Angeles.

Baltazani, Mary. 2002. Focus, Prosodic Phrasing and Hiatus Resolution in Greek. Ms., UCLA.

Bolinger, David. 1965. Forms of English: Accent, Morpheme, Order. Harvard University Press, Cambridge, MA.

Brody, Michael. 1995. Lexico-Logical Form. MIT Press, Cambridge, MA.

Brunetti, Lisa. 2003. A Unification of Focus. Ph.D. diss., University of Florence.

Büring, Daniel. 1995. The 59th Street Bridge Accent: On the Meaning of Topic and Focus. Ph.D. diss., University of Tübingen.

Büring, Daniel. 1997. The Great Scope Inversion Conspiracy. Linguistics \& Philosophy 20: 175-194.

Büring, Daniel \& Gutierrez-Bravo. 2002. Focus-related Word Order Variation without the NSR: A Prosody-based Cross-linguistic Analysis. In Seamas Mac Bhloscaidh, ed., Syntax at Santa Cruz 3, pp. 41-58.

Chen, Matthew. 1987. The Syntax of Xiamen Tone Sandhi. Phonology Yearbook 4: 109-150.

Choi, H.-W. 1996. Topic and Focus in Korean: The Information Partition by Phrase Structure and Morphology. Japanese/Korean Linguistics 6: 545-561.

Chomsky, Noam. 1965. Aspects of the Theory of Syntax. MIT Press, Cambridge, MA.

Chomsky, Noam. 1995. The Minimalist Program. MIT Press, Cambridge, MA.

Chomsky, Noam. 1999. On the Nature of Pragmatics and Related Issues. Brain and Language 68: 393-401.

Chomsky, Noam. 2000. Minimalist Inquiries: The Framework. In Roger Martin, David Michaels \& Juan Uriagereka, eds., Step by Step. MIT Press, Cambridge, MA, pp. 89-155.

Chomsky, Noam. 2001a. Derivation by Phase. In Michael Kenstowicz, ed., Ken Hale: A Life in Language. MIT Press, Cambridge, MA, pp. 1-52.

Chomsky, Noam. 2001b. Beyond Explanatory Adequacy. Ms., MIT, Cambridge, MA.

Chomsky Noam, 2002. On Nature and Language. Cambridge University Press, Cambridge.

Cinque, Guglielmo. 1993. A Null Theory of Phrase and Compound Stress. Linguistic Inquiry 24: 239-297.

Costa, João. 1996. Constituent Order and Constraint Interaction. Ms., HIL/Leiden University; In Seminários de Linguística, University of Algarve.

Costa, João. 1998. Word Order Variation: A Constraint Based Approach. Ph.D. diss., Leiden University.

Diesing, Molly. 1992. Indefinites. MIT Press, Cambridge, MA.

Di Sciullo, Anna Maria \& Edwin Williams. 1987. On the Definition of Word. MIT Press, Cambridge, MA.

Donati, C. \& Marina Nespor. 2003. From Focus to Syntax. Lingua 113: 1119-1142.

Féry, Caroline. 1993. German Intonational Patterns. Niemeyer, Tübingen.

Frascarelli, Mara. 2000. The Syntax-Phonology Interface of Focus and Topic Constructions in Italian. Studies in Natural Language and Linguistic Theory vol. 50. Kluwer, Dordrecht/Boston/London.

Frota, Sonia. 1998. Prosody and Focus in European Portuguese. Garland, New York.

Grillia, Stella. 2004. Ex-situ and In-situ Focus in Greek: A Unified Minimalist Approach. Ms., University of Leiden.

Goldsmith, John. 1976. Autosegmental Phonology. Ph.D. diss., MIT, Cambridge, MA. 
Gussenhoven, Carlos 1984. On the Grammar and Semantics of Sentence Accents. Foris, Dordrecht.

Gussenhoven, Carlos. 1992. Sentence Accents and Argument Structure. In Iggy Roca, ed., Thematic Structure: Its Role in Grammar. Foris, Berlin/New York, pp. 91-106.

Haidou, Konstantina. 2003. Stress Mechanisms in the Syntactic and Phonological Domain of Focus. SOAS Working Papers in Linguistics 13: 135-158.

Haidou, Konstantina. 2004. On the Interaction of Prosodic Phrasing and Information Structure in Greek Word Order Variation. Poster presented at Tone and Intonation in Europe (TIE), Santorini, 9-11 September 2004.

Haidou, Konstantina. Forthcoming. The Syntax-Prosody Interface of Focus Phenomena in Greek. Ph.D. diss., SOAS, University of London.

Halle, Morris \& Alec Marantz. 1993. Distributed Morphology and the Pieces of Inflection. In Kenneth Hale \& S. Jay Keyser, eds., The View from Building 20. MIT Press, Cambridge, MA, pp. 111-176.

Halliday, M. A. K. 1967. Notes on Transitivity and Theme in English, Part II. Journal of Linguistics 3: 199-244.

Hayes, Bruce. 1989. The Prosodic Hierarchy in Meter, Phonetics and Phonology. In P. Kiparsky \& G. Youmans, eds., Rhythm and Meter, Volume 1. Academic Press, San Diego, pp. 201-260.

Horvath, Julia. 1986. Focus in the Theory of Grammar and the Syntax of Hungarian. Foris, Dordrecht.

Hyman, Larry M. \& John R. Watters. 1984. Auxiliary Focus. Studies in African Linguistics 15: 223-273.

Inkelas, Sharon. 1989. Prosodic Constituency in the Lexicon. Ph.D. diss., Stanford University.

Inkelas, Sharon \& Draga Zec. 1995. Syntax-Phonology Interface. In John Goldsmith, ed., Handbook of Phonology. Blackwell, Cambridge, MA, pp. 535-549.

Jackendoff, Ray. 1972. Semantic Interpretation in Generative Grammar. MIT Press, Cambridge, MA.

Jackendoff, Ray. 1997. The Architecture of the Language Faculty. MIT Press, Cambridge, MA.

Kanerva, Jonni. 1989. Focus and Phrasing in Chichewa Phonology. Ph.D. diss., Stanford University.

Kanerva, Jonni. 1990. Focusing on Phonological Phrases in Chichewa. In Sharon Inkelas \& Draga Zec, eds., The Phonology-Syntax Connection. University of Chicago Press, Chicago/London, pp. 145-161.

Kayne, Richard. 1994. The Antisymmetry of Syntax. MIT Press, Cambridge, MA.

Keller, Frank \& Theodora Alexopoulou. 2000. Phonology Competes with Syntax: Experimental Evidence on the Interaction of Word Order and Accent Placement in the Realization of Information Structure. Cognition 79: 301-372.

Kidwai, Ayesha. 2000. XP-Adjunction in Universal Grammar: Scrambling and Binding in Hidi-Urdu. Oxford Studies in Comparative Syntax. Oxford University Press, Oxford.

Kiss, Katalin É. 1995a. Introduction. In Katalin É. Kiss, ed., Discourse Configurational Languages. Oxford University Press, Oxford, pp. 3-27.

Kiss, Katalin É. 1995b. NP Movement, Operator Movement, and Scrambling in Hungarian. In Katalin É. Kiss, ed., Discourse Configurational Languages. Oxford University Press, Oxford, 207-243.

Kiss, Katalin É. 1996. The Focus Operator and Information Focus. Institute of Linguistics, Budapest. 
Kiss, Katalin É. 1998. Identificational Focus versus Informational Focus. Language 74: 245273.

Krifka, Manfred. 1992. A Compositional Semantics for Multiple Focus Constructions. In Joachim Jacobs, ed., Informationsstruktur und Grammatik, Sonderheft der Linguistischen Berichte,

Krifka, Manfred. 1998. Scope Inversion under the Rise-Fall Pattern in German. Linguistic Inquiry 29: 75-112.

Koster, Jan. 1987. Domains and Dynasties. Foris, Dordrecht.

Ladd, D. Robert. 1996. Intonational Phonology. Cambridge University Press, Cambridge.

Lambrecht, Knud. 1994. Information Structure and Sentence Form. Cambridge University Press, Cambridge.

Liberman, M. 1979. The Intonational System of English. Garland Press, New York. (Ph.D. diss., MIT, 1975.)

Liberman, M. \& Alan Prince. 1977. On stress and linguistic rhythm. Linguistic Inquiry 8: 249-336.

McCarthy, John. \& Alan Prince. 1993. Generalized Alignment. Yearbook of Morphology 1993: 79-154

Neeleman, Ad \& Tanya Reinhart. 1998. Scrambling and the PF Interface. In Miriam Butt and Wilhelm Geuder, eds., The Projection of Arguments: Lexical and Compositional Factors. CSLI, Stanford, pp. 309-353

Neeleman, Ad. \& Fred Weerman. 1999. Flexible Syntax: A Theory of Case and Arguments. Kluwer, Dordrecht.

Nespor, Marina \& Irene Vogel. 1982. Prosodic Domains of External Sandhi Rules. In Harry van der Hulst \& Norval Smith, eds., The Structure of Phonological Representations, Vol. 1. Foris, Dordrecht, pp. 225-255

Nespor, Marina \& Irene Vogel. 1986. Prosodic Phonology. Foris, Dordrecht.

Nespor, Marina. 1993. Fonologia. Il Mulino, Bologna.

Nespor, Marina. ed. 1996. Phonology between Words and Phrases. The Linguistic Review.

Odden, David. 1984. Formal Correlates of Focusing in Kimatuumbi. Studies in African Linguistics 15: 275-299.

Philippaki-Warbuton, Irene. 1982. Problimata shetika me tin sira ton oron stis ellinikes protasis. Glossologia 1: 99-107.

Philippaki-Warburton, Irene. 1985. Word Order in Modern Greek. Transactions of the Philological Society, 113-143.

Prince, Alan \& Paul Smolensky. 1993. Optimality Theory: Constraint Interaction in Generative Grammar. Report no. RuCCS-TR-2. Rutgers University Center for Cognitive Science, New Brunswick, NJ.

Reinhart, Tanya. 1995. Interface Strategies. OTS Working Papers. OTS, Utrecht University.

Revithiadou, Anthi. 2003. Focusing in Greek. In Georgia Katsimali, Elena Anagnostopoulou, Aleksis Kalokerinos \& Ioanna Kappa, eds., Proceedings of the $6^{\text {th }}$ International Conference in Greek Linguistics. University of Crete, Rethymnon.

Rizzi, Luigi. 1997. The Fine Structure of the Left Periphery. In Liliane Haegeman, ed., Elements of Grammar: Handbook in Generative Syntax, Kluwer, Dordrecht, pp. 281337.

Rochemont, Michael. 1986. Focus in Generative Grammar. John Benjamins, Amsterdam.

Rochemont, Michael \& Peter Culicover. 1990. English Focus Constructions and the Theory of Grammar. Cambridge University Press, Cambridge.

Rochemont, Michael. 1998. Phonological Focus and Structural Focus. In P. Culicover and L. McNally, eds., The Limits of Syntax. Academic Press, New York, pp. 337-364. 
Schauber, E. 1978. Comparison of English Intonation and Navajo Particle Placement. In D. J. Napoli, ed., Elements of Tone, Stress, and Intonation. Georgetown University Press, Washington, DC, pp. 144-173.

Schmerling, Susan F. 1976. Aspects of English Sentence Stress. Ph.D. diss., University of Texas at Austin.

Schwarzschild, Roger. 1999. GIVENness, AvoidF and Other Constraints on the Placement of Accent. Natural Language Semantics 7: 141-177.

Selkirk, Elizabeth. 1978. On Prosodic Structure and Its Relation to Syntactic Structure. Indiana University Linguistics Club, Bloomington.

Selkirk, Elizabeth. 1981. On Prosodic Structure and its Relation to Syntactic Structure. In Thorstein Fretheim, ed., Nordic Prosody II, TAPIR, Trodheim. pp. 111-140.

Selkirk, Elizabeth. 1984. Phonology and Syntax. MIT Press, Cambridge, MA.

Selkirk, Elizabeth. 1986. On Derived Domains in Sentence Phonology. Phonology Yearbook 3: 371-405.

Selkirk, Elizabeth \& Shen. T. 1990. Prosodic Domain in Shanghai Chinese. In Sharon Inkelas \& Draga Zed, eds., The Phonology-Syntax Connection. University of Chicago Press, Chicago/London, pp. 145-161.

Selkirk, Elizabeth. 1995. Sentence Prosody, Intonation, Stress and Phrasing. In John A. Goldsmith, ed., The Handbook of Phonological Theory. Blackwell, Oxford.

Sifaki, Evangelia. 2003. EPP Satisfiers: Verb-Initial Orders in Greek. Ph.D. diss., University of York.

Steedman, Mark. 2000. Information Structure and the Syntax-Phonology Interface. Linguistic Inquiry 31: 649-689.

Szabolcsi, Anna. 1981. The Semantics of Topic-Focus Articulation. In Jeroen Groenendijk, Theo Janssen \& Martik Stokhof, eds., Formal Methods in the Study of Language. Matematisch Centrum, Amsterdam, pp. 513-541.

Szendröi Kriszta. 2001. Focus and the Syntax-Phonology Interface. Ph.D. diss., UCL, London.

Truckenbrodt, Hubert. 1995. Phonological Phrases: Their Relation to Syntax,Focus and Prominence. Ph.D. diss., MIT, Cambridge, MA.

Truckenbrodt, Hubert. 1999. On the Relation between Syntactic Phrases and Phonological Phrases. Linguistic Inquiry 30: 2 219-255.

Tsimpli, Ianthi-Maria. 1990. The Clause Structure and Word Order of Modern Greek. UCL Working Papers in Linguistics 2: 226-255.

Tsimpli, Ianthi-Maria. 1995. Focussing in Modern Greek. In Katalin É. Kiss, ed., Discourse Configurational Languages. Oxford University Press, New York, pp. 176-206.

Tsimpli, Ianthi-Maria. 1997. Individual and Functional Readings for Focus, WH-and Negative Operators: Evidence from Greek. In Brian D. Joseph, Geoffrey C. Horrocks and Irene Philippaki-Warburton, eds., Themes in Greek Linguistics II. Current Issues in Greek Linguistics 159, Benjamins, pp. 197-227.

Tsiplakou, Stavroula. 1998. Focus in Greek: Its Structure and Interpretation. Ph.D. diss., School of Oriental and African Studies. University of London.

Tzanidaki, Dimitra. 1994. Word-order in Modern Greek. Ph.D. diss., UCL, London.

Vallduví, Enric. 1992. Informational Packaging: A survey. Research Paper, University of Edinburgh.

Vallduví, Enric \& E. Engdahl.1996. The Linguistic Realisation of Information Packaging. Linguistics 34: 459-519.

Vallduví, Enric \& Vilnuka 1998. On Rheme and Kontrast. In Peter Culicover and Louise McNally, eds., The Limits of Syntax. Syntax and Semantics 29. Academic Press. pp. 79108 
Watters, John R. 1979. Focus in Aghem: A Study of its Formal Correlates and Typology. In Larry M. Hyman, ed., Aghem Grammatical Structure: Southern California Occasional Papers in Linguistics 7. University of Southern California, Los Angeles, pp. 137-97.

Williams, Edwin. 2003. Representation Theory. MIT Press, Cambridge, MA.

Zec, Draga \& Sharon, Inkelas. 1990. Prosodically constrained syntax. In Sharon Inkelas and Draga Zec, eds., The Phonology-Syntax Connection. University of Chicago Press, pp. 365-378.

Zubizarreta, Maria-Luisa. 1994. Grammatical Representation of Topic and Focus; Implications for the Structure of the Clause. Cuardenos de Linguistica del I. U. Ortega y Gasset 2: 181-208.

Zubizarreta, Maria-Luisa. 1998. Prosody, Focus and Word Order. MIT Press, Cambridge, MA. 